doi:10.1016/j.gca.2004.04.007

\title{
Association of calcium with colloidal particles and speciation of calcium in the Kalix and Amazon rivers
}

\author{
Ralf Dahlqvist, ${ }^{1,2, *}$ Marc F. Benedetti, ${ }^{3}$ Karen Andersson, ${ }^{4}$ David Turner, ${ }^{4}$ Tobias Larsson, ${ }^{4}$ \\ BJÖRn STOLPE, ${ }^{4}$ AND JOHAN INGRI ${ }^{5}$ \\ ${ }^{1}$ Department of Geology and Geochemistry, Stockholm University, 10691 Stockholm, Sweden \\ ${ }^{2}$ Laboratory for Isotope Geology, Swedish Museum of Natural History, Box 50007,104 05 Stockholm, Sweden \\ ${ }^{3}$ Laboratorie de Géochimie et Métallogénie, UMR-CNRS 7047, Universite Pierre et Marie Curie, 4 place Jussieu, 75005 Paris, France \\ ${ }^{4}$ Department of Chemistry, Analytical and Marine Chemistry, Göteborg University, 41296 Göteborg, Sweden \\ ${ }^{5}$ Division of Applied Geology, Luleå University of Technology, 97187 Luleå, Sweden
}

(Received November 6, 2003; accepted in revised form April 21, 2004)

\begin{abstract}
A considerable amount of colloidally bound $\mathrm{Ca}$ has been detected in water samples from Amazonian rivers and the Kalix River, a sub-arctic boreal river. Fractionation experiments using several analytical techniques and processing tools were conducted in order to elucidate the matter. Results show that on average $84 \%$ of the total $\mathrm{Ca}$ concentration is present as free $\mathrm{Ca}$. Particulate, colloidal and complexed Ca constitute the remaining $16 \%$, of which the colloidal fraction is significant. Ultrafiltration experiments show that the colloidal fraction in the sampled Amazonian rivers and the Kalix River range between $1 \%$ and $25 \%$.

In both the Amazonian and the Kalix rivers the technique of cross-flow ultrafiltration was used to isolate particles and colloids. The difference in concentration measured with ICP-AES and a Ca ion-selective electrode in identical samples was used to define the free $\mathrm{Ca}$ concentration and thus indirectly the magnitude of the particulate, colloidal and complexed fractions. Results from the Kalix and Amazonian rivers are in excellent agreement. Furthermore, the results show that the colloidal concentrations of Ca can be greatly overestimated (up to 227\%) when conventional analysis and calculation of ultrafiltration data is used due to retention of free $\mathrm{Ca}$ ions during the ultrafiltration process. Calculation methods for colloidal matter are presented in this work, using complementary data from ISE analysis.

In the Kalix River temporal changes in the fractionation of $\mathrm{Ca}$ were studied before, during and after a spring-flood event. Changes in the size distribution of colloidally associated $\mathrm{Ca}$ was studied using FlFFF (Flow Field-Flow Fractionation) coupled on-line to a HR ICP-MS. The FlFFF-HR ICP-MS fractograms clearly show the colloidal component of $\mathrm{Ca}$, supporting the ultrafiltration findings. During winter conditions the size distribution of colloidally associated $\mathrm{Ca}$ has a concentration maximum at $\sim 5$ to $10 \mathrm{~nm}$ in diameter, shifting to smaller sizes $(<5 \mathrm{~nm})$ during and after the spring flood. This shift in size distribution follows a change in the river during this period from ironoxyhydroxy colloids being the most important colloidal carrier phase to humic substances during and after the spring flood.

WHAM and NICA-Donnan models were used to calculate the amount of colloidally bound $\mathrm{Ca}$. The results similar for both models, show that on average $16 \%$ of the Ca may be associated to a colloidal phase, which is in broad agreement with the measurements. Copyright ${ }^{\circ} 2004$ Elsevier Ltd
\end{abstract}

\section{INTRODUCTION}

Speciation, bio-availability and mobility of major and trace elements and organic compounds can be strongly influenced by colloidal material (Wells and Goldberg, 1991; Tipping and Hurley, 1992; Benedetti et al., 1996). Colloids in natural waters are theoretically defined as particles not affected by sedimentation. For practical reasons, however, colloidal material is operationally defined as sub-micrometer particles, and are usually isolated by some kind of filtration. Due to the small size of colloidal particles, this fraction has a very large surface area with potential to bind significant amounts of trace elements and organic pollutants, thus acting as a transporting agent where sedimentation otherwise may be an important process.

The major focus has traditionally been to study trace elements and their adsorption to organic and inorganic surfaces present in the water. Our studies in Amazonian rivers and a

* Author to whom correspondence should be addressed (ralf.dahlqvist@ nrm.se). subarctic boreal river show that much remains to be understood concerning the dissolved and colloidal speciation of the major element $\mathrm{Ca}$ and its carrier phases in natural fresh waters.

Colloidal material is often collected using Cross-flow (ultra)filtration (CFF) to study the distribution of trace elements and organic matter in natural waters (Guo et al., 1994; Eyrolle et al., 1996). So far, CFF has mainly been used to collect marine colloids and there are several evaluations of the performance of different filtration systems used with high-salinity waters (Gustafsson et al., 1996; Greenamoyer and Moran, 1996; Dai et al., 1998). Ultrafiltration of fresh waters seems to be more demanding, and systematic CFF experiments for fresh waters are sparse (Buffle et al., 1978; Guo et al., 2001; Larsson et al., 2002). Metal adsorption to a neutral membrane during ultrafiltration of lake water was reported by Salbu et al. (1985). This could result in low recoveries as one potential problem and possibly question CFF as a method for separating particulate and colloidal material in natural fresh waters. Another problem recently proposed about $\mathrm{CFF}$ is the retention of free major ions ( $\left.\mathrm{Ca}, \mathrm{Mg}, \mathrm{SO}_{4}\right)$ (Guo et al., 2001). This causes a serious problem when handling natural samples, as no 
distinction can be made between retention of free ions and colloids/particles with conventional analysis. Analysis by e.g., Inductively Coupled Plasma-Atomic Emission Spectroscopy (ICPAES) or ICP-Mass Spectrometry (ICP-MS) is insufficient to make this distinction, since it only provides the total concentration for each fraction. Thus, the amount of colloidal material in a retentate solution will be overestimated if significant retention of free ions occurs.

A technique with good potential for size fractionation and analysis of colloidal material, where the pretreatment is both mild and rapid, is Field-Flow Fractionation (FFF). Colloids are separated according to their ability to diffuse against a field perpendicular to the carrier flow. The most appropriate FFF technique for smaller colloids $(1-50 \mathrm{~nm})$ is Flow FFF (FIFFF) where a cross flow provides the perpendicular field in the separation column (Beckett and Hart, 1993; Giddings, 1993) and the smallest colloids have the fastest diffusion rates and are eluted first (Beckett and Hart, 1993).

A recent study using Flow Field-Flow Fractionation (FIFFF) to characterize colloidal matter in a creek in Sweden (Lyvén et al., 2003), showed that a significant amount of $\mathrm{Ca}$, associated with C-rich material, was present in the colloidal phase. A clear distinction could also be made between $\mathrm{C}$-rich and Fe-rich colloids in the creek water.

When compared to ultrafiltration, FFF has the ability to describe the nature of colloidal material in more detail since quantitative determinations for the continuous size fractionations are possible. CFF, on the other hand, is restricted to filter membranes with fixed pore sizes.

To determine whether free ions are retained during ultrafiltration of natural samples, the concentration of free ions needs to be determined in the different CFF-fractions (feed, permeate and retentate). To enable compensation for this artifact, parallel to using ICP-AES measurements, a Ca ISE was used to determine the concentration of free $\mathrm{Ca}$ ions in each CFF-fraction during the studies in the Kalix and Amazonian rivers.

The Amazonian and Kalix rivers are very different regarding climate, geology, drainage area size, discharge, topography and many other parameters. By partly using the same analysis and fractionation/speciation tools, data presented here partly indicate the same behavior in Ca speciation and fractionation in the Kalix and Amazonian rivers. A significant amount of colloidally bound $\mathrm{Ca}$ could for instance be detected in both river systems. In colloidal material Ca may be adsorbed to negatively charged surfaces of colloids or bound by fibrillar polysaccharides extracted by algae and bacteria. A summary on the subject and a discussion about different types of aquatic colloids and their behavior is presented in Buffle et al. (1998).

Together the Kalix and Torne rivers form the largest pristine river system in Europe. During the winter period the area is covered with snow and ice, and the spring flood gives rise to a dramatic increase in water runoff in the river, often by a factor of 20 to 25 in volumetric flow over a few days. These are large variations compared to the two-fold increase of runoff observed in the Amazon River (Gibbs, 1972). The origin of the water in the Kalix River also changes drastically during this period, from consisting mostly of ground water during winter, to having a large contribution of meltwater from the snow cover in the woodland area during peak flood, and finally water from the mountainous region later during the spring flood.
This study on calcium fractionation is part of the 'Kalix 2002' project in which we have studied temporal changes in the geochemistry of colloids in the Kalix River from winter conditions, through the spring flood event and into summer conditions. An overview of the major colloidal carrier phases, major elements and some of the trace elements associated with the colloids, as well as background data on discharge and other significant parameters will be presented in a separate publication. There will also be papers on the colloidal geochemistry of the rare earth elements; carbon speciation in the Kalix River; as well as a comparison of using the two different techniques CFF and FIFFF for studies of colloids.

\section{METHODS}

\subsection{Definitions}

The many different methods and techniques for processing, analysis and calculation described in this article call for short descriptions of the terminology used and the different fractions handled during sample treatment.

\subsubsection{Methods and units}

- CFF: Cross-flow filtration. An ultrafiltration method by which colloidal or particulate material can be collected and concentrated in a solution. Also termed tangential flow filtration by some authors.

- FFF: Field-flow fractionation. A membrane-based chromatographylike technique by which the continuous size distribution of colloidal material can be quantitatively determined.

- FlFFF: Flow FFF. During the 'Kalix 2002' project the method of flow FFF (FIFFF) was used. See section 2.2.3 for a description of this method.

- ISE: Ion-selective electrode. An analysis technique by which the concentration of free ions is determined. Theoretically similar to the glass electrode technique used to measure $\mathrm{pH}$.

- Da: Dalton (Da) is a unit equal to the unified atomic mass unit (u), and is widely used in biochemistry. Its use is accepted and supported although it has not been approved by the Comité international des poids et mesures (CIPM). A pore size of $1000 \mathrm{Da}(1 \mathrm{kDa})$ approximately equals the size of a globular protein which is $2 \mathrm{~nm}$ in diameter. A pore size of 10,000 Da equals $\sim 5 \mathrm{~nm}$.

\subsubsection{Fractions}

- Prefiltered: water passing a $100-\mu \mathrm{m}$ nylon mesh.

- Permeate: The solution which passes through the membrane during an ultrafiltration. Also termed filtrate by some authors.

- Retentate: The solution collected during an ultrafiltration in which material larger than the pore size of the membrane is collected and concentrated. This material can include both particles and colloids depending on the pore size of the filter.

- c.f.: Concentration factor (c.f.). This is the ratio between the initial total volume of a sample and the volume of the retentate (c.f. = $\left.V_{\text {tot }} / V_{\text {ret }}\right)$. The number is used to calculate the colloidal or particulate concentration from the retentate solution. See section 2.1.3 for methods to calculate the colloidal concentration.

- CFR: The cross-flow ratio (CFR) is calculated by dividing the retentate flow with the permeate flow. A CFR $>15$ has been recommended to avoid loss of material and low recoveries (Larsson et al., 2002).

- Particles: Material in the size fraction $>0.22 \mu \mathrm{m}$. Particles are collected in the retentate fraction during ultrafiltration using the $0.22-\mu \mathrm{m}$ filter.

- Colloids: Defined here as material between $1 \mathrm{kDa}$ and $0.22 \mu \mathrm{m}$ for the Kalix project and between $5 \mathrm{kDa}$ and $0.22 \mu \mathrm{m}$ for the Amazon project. The colloids are collected in the retentate fraction during ultrafiltration using the $1-$ and $5-\mathrm{kDa}$ filters.

- Colloidal carrier phase: Used in this article and previous work (Lyvén et al., 2003) to distinguish between different types of col- 
loids, not only by size fractionation but also by chemical nature, and to signify how different elements are associated to these colloids.

- Complexed: This fraction is defined here as the amount of $\mathrm{Ca}$ in the 1- (Kalix) and 5-kDa (Amazon) permeates which can not be detected by ISE analysis.

- Free $\mathrm{Ca}$ : This is the concentration of free $\mathrm{Ca}$ ions as measured by ISE.

\subsubsection{Calculation methods for the colloidal fraction}

Ultrafiltration is used to collect and enrich colloids in a retentate solution in a controlled fashion for analysis. The technique is based on the assumption that only colloids larger than the pore size of the used filter are enriched and that the matrix of permeable species remain unaltered, but previous work (e.g., Viers et al., 1997; Guo et al., 2001) and data presented here suggest retention of free Ca. Appropriate measures have to be taken to correct for this artifact.

The normal method to calculate the concentration of the colloidal fraction is to use measurements by ICP-AES, or other techniques measuring totals metal concentrations.

$[$ colloidal $]=\left[(1 \mathrm{kDa} \text { retentate })_{\mathrm{ICP}}-(1 \mathrm{kDa} \text { permeate })_{\mathrm{ICP}}\right] / c . f . \quad(1)$

where c.f. is the concentration factor.

$$
\text { c.f. }=(\text { retentate vol. + permeate vol. }) / \text { retentate vol. }
$$

Alternatively, the colloidal concentration can be calculated using ICPAES results from the $0.22-\mu \mathrm{m}$ permeate and the $1-\mathrm{kDa}$ permeate solutions.

$$
\text { [colloidal }_{\mathrm{IkDa}^{\mathrm{kD}} 0.22 \mu \mathrm{m}}=[<0.22 \mu \mathrm{m}]_{\mathrm{ICP}}-[<1 \mathrm{kDa}]_{\mathrm{ICP}}
$$

The first two methods have only used results from ICP-AES analysis to calculate the concentration of colloidally associated $\mathrm{Ca}$. In Eqn. 4, results from both ICP-AES and ISE analyses in the same $<0.22-\mu \mathrm{m}$ fraction are used.

$$
\text { [colloidal }_{<0.22 \mu \mathrm{m}}=[<0.22 \mu \mathrm{m}]_{\mathrm{ICP}}-[<0.22 \mu \mathrm{m}]_{\mathrm{ISE}}
$$

Note that this method also includes colloidal and complexed $\mathrm{Ca}<$ $1 \mathrm{kDa}$.

Finally, the colloidal concentration can also be calculated by using ICP and ISE results from the $1-\mathrm{kDa}$ retentate solution.

$$
[\text { colloidal }]_{\mathrm{kDa}-0.22 \mu \mathrm{m}}=\left[(1 \mathrm{kDa} \text { ret })_{\mathrm{ICP}}-(1 \mathrm{kDa} \text { ret })_{\mathrm{ISE}}\right] / c . f
$$

Comparisons between these different methods for water samples collected in the Kalix and Amazonian Rivers are presented in section 3.2. The significance of the methods will be addressed and recommendations suggested.

\subsection{The 'Kalix 2002' Project}

The Kalix River in northern Sweden (Fig. 1) is part of a large pristine river system (Dynesius and Nilsson, 1994) and is classified as a river of medium size in the boreal zone. The Kalix River is unregulated: no man-made dams or other constructions influence the water discharge. The mean annual discharge is $296 \mathrm{~m}^{3} \mathrm{~s}^{-1}$ with low flows $<100 \mathrm{~m}^{3} \mathrm{~s}^{-1}$ during winter, and high flows up to $1600 \mathrm{~m}^{3} \mathrm{~s}^{-1}$ during spring flood. The drainage area is $2.410^{4} \mathrm{~km}^{2}$ ( $\sim 5 \%$ of Sweden's land surface area) and stretches from the river mouth located by the Gulf of Bothnia to the Scandinavian part of the Caledonian mountain range in the north-west. About $60 \%$ of the water in the nearby Torne River drains via a bifurcation into the Kalix River, and together these two rivers constitute the largest unregulated river system in northern Europe. In earlier studies of the Kalix River by ultrafiltration, indications of two dominant colloidal phases were found; an organic-rich phase, probably consisting of humic material, and an Fe-rich (Fe-oxyhydroxides) inorganic phase (Ingri et al., 2000).

The basement in the catchment can be divided into two different areas. The Caledonides in the north-west cover $\sim 5 \%$ of the basement and are mainly mica schist, quartzite and amphibolite (Gee and Zachrisson, 1979). The rest of the basement is Precambrian bedrock of granitic composition with features of acidic, intermediate and basic

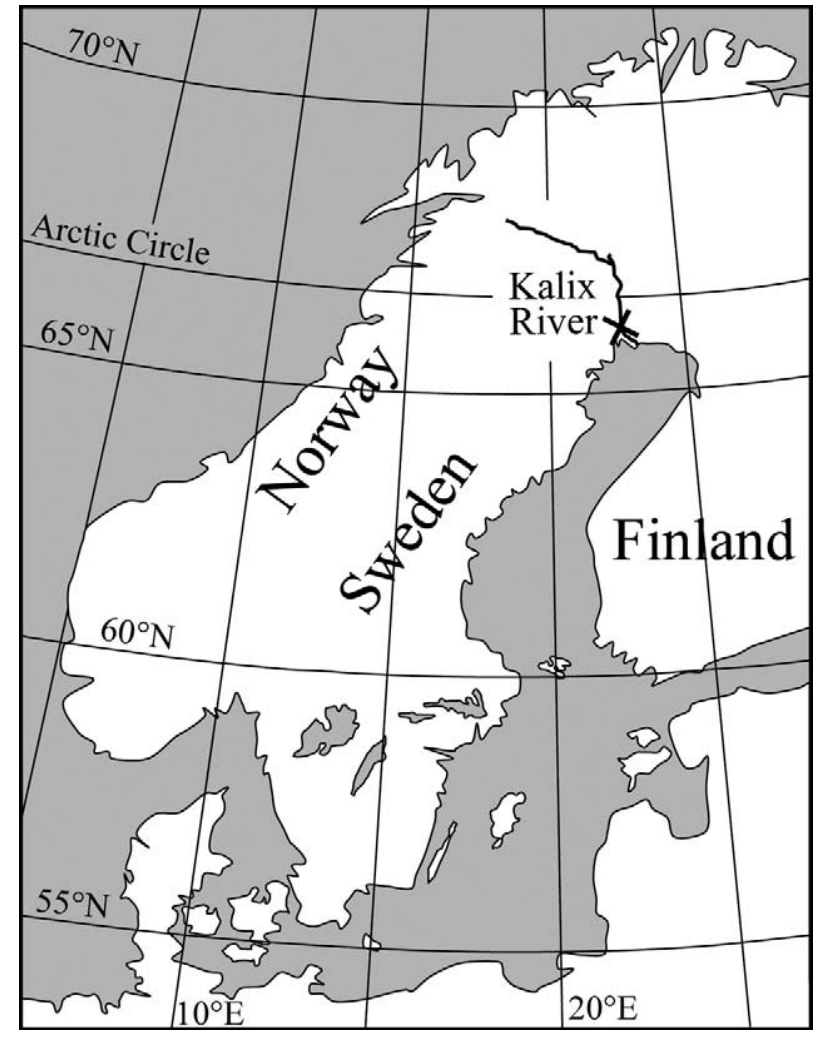

Fig. 1. The Kalix River catchment in northern Sweden. Most is situated north of Arctic Circle but no part is within the permafrost region. One quarter of the area is covered by wetlands. The sampling station for the 'Kalix 2002' project, marked by X, is close to the river mouth.

volcanic rocks along with sedimentary rocks, more or less affected by metamorphism (Gaal and Gorbatschev, 1987). The quaternary cover is dominated by till deposited during the last glacial period which ended $\sim 8700 \mathrm{yr}$ ago in the area. The till now has a well-developed podzol profile (Fromm, 1965). Peatland covers $\sim 20 \%$ of the catchment. Some postglacial sediments are deposited close to the river and its contributors. Coniferous forests of spruce and pine cover $55 \%$ to $65 \%$ of the area. The average annual temperature and precipitation are $\sim 0.2^{\circ} \mathrm{C}$ and $\sim 500 \mathrm{~mm}$, respectively.

\subsubsection{Sampling}

Sampling was performed in the Kamlunge rapids, close to the river mouth, on 10 occasions from February to June 2002. Water samples $(50 \mathrm{~L})$ were prefiltered in the field with a $100-\mu \mathrm{m}$ nylon mesh filter mounted in a 142-mm Geotech polycarbonate filter holder, and collected in two 25-L polyethene (PE) containers. The two exceptions to this are the sample collected in February when no prefiltration was performed, and the March sample when a $25 \mu \mathrm{m}$ membrane filter cartridge was used for prefiltration. No other pretreatment was made. River water was flushed through the sampling system for a few minutes to condition it and to and remove possible contaminating particles before any sample was collected. The containers were thereafter immediately transported to the laboratory where ultrafiltration (within $2 \mathrm{~h}$ ) and FlFFF processing (within $3 \mathrm{~h}$ ) commenced. Due to the short storage time no significant alteration of the samples was expected. All equipment, i.e., filter holder, nylon mesh, tubing and containers, was acidcleaned in $5 \% \mathrm{HNO}_{3}$ for at least $48 \mathrm{~h}$ and rinsed in ultrapure MilliQwater $(>18 \mathrm{M} \Omega \mathrm{cm})$ before use.

Water temperature, $\mathrm{pH}$ and conductivity were monitored in the field during sampling with either with a Hydrolab MiniSonde3 or a 


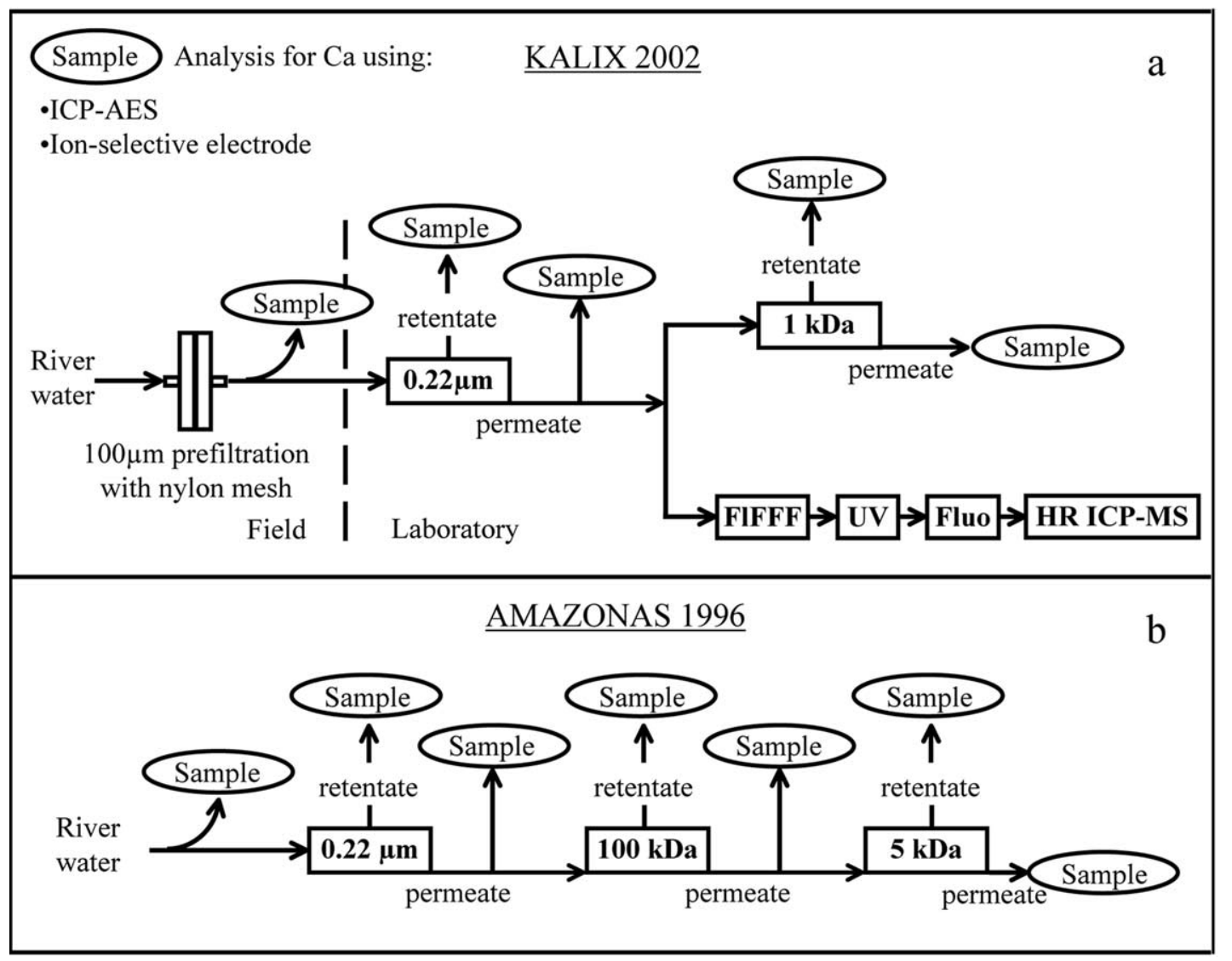

Fig. 2. Schematic set up for the ultrafiltrations and FIFFF processing used during the 'Kalix 2002' river study (a) and the 'Rio Purús Cruise' (b).

DataSonde4a. The instruments were carefully calibrated before each sampling, and data was collected for at least $30 \mathrm{~min}$.

Prefiltered samples were also collected and analyzed for total organic carbon (TOC) and fluorescence (humic substances measured as micrograms per liter of quinine sulphate) at excitation/emission wavelengths of 350/450 nm (Jasco FP - 777 Spectrofluorometer). TOC and fluorescence were measured in all permeate and retentate fractions from ultrafiltrations.

\subsubsection{Ultrafiltration}

Figure 2a shows the sampling and ultrafiltration setup used during this study. No samples were drawn from the permeate or retentate lines during the ultrafiltration. Instead, bulk samples of permeate and retentate were collected after completed ultrafiltration. A Millipore Pellicon2 acrylic filter holder and a high performance peristaltic Watson Marlow pump was used. Three types of Millipore Cassette filters (0.46 $\mathrm{m}^{2}$ ) were used; $0.22 \mu \mathrm{m}$ and $1 \mathrm{kDa}$. On one occasion a 1-MDa filter was used as substitute for the $0.22-\mu \mathrm{m}$ filter. The membrane material for the $0.22-\mu \mathrm{m}$ filter was polyvinylidene fluoride (PVDF). The 1-kDa and 1-MDa filters were made of regenerated cellulose. It should be noted that the cutoff for an ultrafilter (in daltons) is a nominal value, and that the real cutoff (in nanometers) for a colloidal particle depend upon its chemical composition and structure, and on operational settings during the ultrafiltration processing (Larsson et al., 2002).

All filters were first rinsed with large amounts of ultrapure water to remove the organic storage solution. A complete cleaning cycle was then performed with base and acid solutions according to the specifications given by the manufacturer. These solutions were prepared from ultrapure water, p.a. $\mathrm{NaOH}$ and p.a. $\mathrm{HCl}$. The filters were thoroughly rinsed with ultrapure water between the base and acid solutions and after the acid solution. All together, each filter was rinsed with $\sim 100 \mathrm{~L}$ of ultrapure solution before being used. Each filter was also preconditioned with $\sim 2 \mathrm{~L}$ of sample solution before starting the actual ultrafiltration. A new cleaning cycle using $\mathrm{NaOH}$ and $\mathrm{HCl}$ was then performed before the processing of each new sample. The filters were stored in air tight plastic bags in the dark at $\sim 5^{\circ} \mathrm{C}$ between ultrafiltrations.

The collected water samples $(50 \mathrm{~L})$ were immediately ultrafiltered with the $0.22-\mu \mathrm{m}$ filter upon arrival to the laboratory. The retentate solution was reduced to $\sim 3 \mathrm{~L}$ before closing the permeate line. The $0.22-\mu \mathrm{m}$ ultrafiltration usually lasted for $\sim 3 \mathrm{~h}$. The permeate fraction was collected in clean 25-L PE containers.

Roughly $25 \mathrm{~L}$ of the $0.22-\mu \mathrm{m}$ permeate was then filtered with the $1-\mathrm{kDa}$ filter (Fig. 2a), and a fraction of the $0.22-\mu \mathrm{m}$ permeate was analyzed by FIFFF-HR ICP-MS. The volume of the retentate solution from the $1 \mathrm{kDa}$ filtration was reduced to $\sim 1.5 \mathrm{~L}$. All retentate and permeate solutions were sampled for analysis with ICP-AES and with an ion-selective electrode for free $\mathrm{Ca}$. The ultrafiltrations described above of a sample $(0.22 \mu \mathrm{m}$ and $1 \mathrm{kDa})$ were completed within $14 \mathrm{~h}$ after collection.

During all ultrafiltrations, the retentate volume was kept constant at $\sim 4 \mathrm{~L}$ until the end of each filtration when the volume was reduced. This was achieved by continuously transferring feed solution from the 25- $\mathrm{L}$ container to a 5- $\mathrm{L}$ retentate-flask at the same rate as the permeate flow. This technique makes the concentration factor increase at a linear rate until the supply of feed solution runs out after which the concentration factor increases exponentially.

The settings used during ultrafiltration, including membrane material, retentate and permeate flow and mean recoveries for $\mathrm{Ca}$ are presented in Table 1. At the end of each filtration, the retentate solution was allowed to circulate through the system with the permeate line closed for $10 \mathrm{~min}$ to obtain better recoveries (Benner, 1991). All fractions from the ultrafiltrations were analyzed for total Ca-concen- 
Table 1. Ultrafiltration settings during the 'Kalix 2002' project.

\begin{tabular}{|c|c|c|c|c|c|c|}
\hline Filter type & Material & $\begin{array}{l}\text { Retentate } \\
\text { flow }\end{array}$ & $\begin{array}{l}\text { Permeate } \\
\text { flow }\end{array}$ & CFR & $\begin{array}{c}\text { Average } \\
\text { c.f. }\end{array}$ & $\begin{array}{c}\text { Average } \mathrm{Ca} \\
\text { recovery }\end{array}$ \\
\hline Double $0.22 \mu \mathrm{m}$ & PVDF & $7.8 \mathrm{~L} / \mathrm{min}$ & $250 \mathrm{~mL} / \mathrm{min}$ & 31 & 16.1 & $0.95(n=7)$ \\
\hline Double $1 \mathrm{kDa}$ & Regenerated cellulose & $4.0 \mathrm{~L} / \mathrm{min}$ & $75 \mathrm{~mL} / \mathrm{min}$ & 53 & 9.6 & $0.82(n=10)$ \\
\hline Single $1 \mathrm{MDa}^{\mathrm{a}}$ & Regenerated cellulose & $4.8 \mathrm{~L} / \mathrm{min}$ & $250 \mathrm{~mL} / \mathrm{min}$ & 19 & 16.9 & $0.93(n=1)$ \\
\hline
\end{tabular}

${ }^{\text {a }}$ Used once on May 6 as replacement for $0.22 \mu \mathrm{m}$ filter.

tration with a ICP-AES (ARL 3560) according to EPA-method 200.7, and with Ca ISE. Replicates were not performed and the uncertainty of a single ICP-AES measurement is better than $5 \%$.

\subsubsection{FlFFF-ICPMS}

The FlFFF-ICPMS system setup and operating procedure has previously been described in detail in a separate publication (Hassellöv et al., 1999). During the Kalix 2002 project three detectors were used in series after the FIFFF; a flow-through UV detector (Jasco UV-975), a flow-through fluorescence detector (Jasco-FP 920) and finally a high resolution ICP-MS (ELEMENT, Thermo Finnigan), allowing determination of elemental composition as a function of colloid size within $100 \mathrm{~min}$. A quantitative on-channel preconcentration procedure was used to enable the injection of an FlFFF sample volume of $45 \mathrm{~mL}$ (Lyvén et al., 1997). The FFF channel comprises an accumulation-wall membrane and a thin Mylar spacer clamped between two PMMA blocks. The accumulationwall consists of an ultrafilter membrane (1-kDa MWCO, Omega, PALL-Filtron).

The entire system has been made virtually metal-free and tracemetal clean techniques have been employed to avoid metal contamination. The FlFFF carrier $\left(15 \mathrm{mmol} / \mathrm{L} \mathrm{NH}_{4} \mathrm{NO}_{3}, \mathrm{pH}\right.$ 7.0) has been optimized to resemble the natural chemical environment and to be compatible with the demands of both the FIFFF separation and the ICP-MS with respect to ionic strength and $\mathrm{pH}$. Using $\mathrm{NH}_{4} \mathrm{NO}_{3}$ as buffer, instead of borate $/ \mathrm{NaCl}$ which was used in Lyvén et al. (1997), has the advantage of avoiding salt deposits on the ICP-MS cones, thus minimizing the drop in sensitivity during a FlFFFICP-MS run.

At the FIFFF-ICPMS interface the FIFFF outflow is acidified and an indium standard is added, by which the FIFFF outflow is diluted 1:1. The operating conditions for the FIFFF and ICP-MS are listed in Table 2. The detection limit for Ca was $2.7 \mathrm{nmol} / \mathrm{L}\left(0.11 \mu \mathrm{g} \mathrm{L}^{-1}\right)$ and for $\mathrm{Fe} 0.6 \mathrm{nmol} / \mathrm{L}$ $\left(0.025 \mu \mathrm{g} \mathrm{L}^{-1}\right)$.

The $\mathrm{Ca}$ and $\mathrm{Fe}$ signals obtained from the ICP-MS were converted to concentration using blanks and standards prepared in the same matrix as the sample, $7.5 \mathrm{mmol} / \mathrm{L} \mathrm{NH}_{4} \mathrm{NO}_{3}$ and $1 \%(\mathrm{v} / \mathrm{v})$ nitric acid. The concentration versus retention time curve was integrated to give the total peak area. The area was then converted to the amount of metal by multiplying by the flow rate and the dilution factor in the FFF-ICP-MS interface. The amount of metal found in the fractionated peaks was then compared with the total amount of metal injected (sample volume multiplied by filtered total sample concentration). The total filtered sample concentration was determined by measuring an acidified filtered sample. UV absorbance at $270 \mathrm{~nm}$, Fluorescence at 350/450 nm (excitation/emission) were used to obtain size distributions of colloidal C, but the $\mathrm{C}$ fractograms were not quantified.

The raw fractograms (UV, Fluorescence and elemental concentration as a function of the retention time) were converted into frequency distributions against size or molecular weight. Size was estimated as the hydrodynamic diameter distribution from FlFFF theory (Giddings et al., 1976; Beckett et al., 1987).

All FlFFF carrier solution reagents used were of analytical grade dissolved in Milli-Q water. Metal standards were prepared by dilution of $10 \mathrm{mg} \mathrm{L}^{-1}$ mixed standards (SPEX CertiPrep, Glen Specra Reference Materials, Stanmore, England) and spikes from dilution of 1000 $\mathrm{mg} \mathrm{L}^{-1}$ stock standard solutions (Merck). High purity acid was prepared in a clean laboratory by subboiling point quartz distillation of analytical grade $\mathrm{HNO}_{3}$ (Merck).

\subsubsection{Ca ISE measurements}

The concentration of free $\mathrm{Ca}$ ions was measured using a liquid membrane (PVC) Ca ion-selective electrode (WTW, Germany), and a double junction $\mathrm{pH}$ sensor (Polilyte Bridge Lab by Hamilton, UK) as a reference electrode. The two electrodes were connected to a digital multimeter which measured the DC potential $(\mathrm{mV})$ with an accuracy of two decimal points $( \pm 0.01 \mathrm{mV})$. The multimeter was in turn connected to a laptop PC equipped with software able to continuously record data and graphically display the DC potential. This setup facilitated observation of the potential readings during measurements. The temperature of all standard solutions and samples was allowed to stabilize $\left(\sim 20^{\circ} \mathrm{C}\right)$ before any measurements were started. Samples were collected in acid-washed 250-mL PE plastic bottles with wide necks to allow both sampling and measurement in the same bottle. All measurements were performed while stirring with a Teflon coated magnet. The data recording software was set to register the potential every two seconds and was started as the electrodes were lowered into the solution. When a stable potential was observed (usually after 3-4 min), a minimum of 30 data points were collected for each standard or sample. An average concentration and standard deviation were calculated from these data. Figure 3 shows typical calibration curves for the ISE. Solid $\mathrm{Ca}\left(\mathrm{NO}_{3}\right)_{2}$ (p.a.) and ultrapure water was used to make five standard solutions ranging from 20 to $875 \mu \mathrm{mol} / \mathrm{L}$. The average standard deviation $(1 \sigma)$ of a sample measurement was $\sim 3 \%$.

\subsubsection{Modelling of $\mathrm{Ca}$ in the kalix river}

Calcium speciation in the Kalix river samples was modelled using the Windermere Humic Acid Model (WHAM), version 6.0.6 (Centre for Ecology and Hydrology, NERC, UK). This software uses Tipping's

Table 2. Fractionation conditions and ICP-MS instrument operating parameters for flow FFF ICP-MS.

Flow FFF conditions:

Channel dimensions $(\mathrm{cm})$

Channel volume $(\mathrm{mL})$

Channel flow rate $(\mathrm{mL} / \mathrm{min})$

Cross flow rate $(\mathrm{mL} / \mathrm{min})$

Relaxation time (s)

UV wavelength $(\mathrm{nm})$

Fluorescence wavelengths (nm) 350/450

ICP-MS (Thermo Finnigan ELEMENT 1) instrument settings and operation parameters:

$\mathrm{RF}$ generator frequency $(\mathrm{MHz}) \quad 27$

$\mathrm{RF}$ power $(\mathrm{W})$

Cool gas flow rate $(\mathrm{L} / \mathrm{min})$

Auxillary gas flow rate $(\mathrm{L} / \mathrm{min})$

Sample gas flow rate $(\mathrm{L} / \mathrm{min})$

Ion lens settings

Torch

Nebulizer

Spray chamber

Sample cone

Skimmer cone

Sample takeup rate $(\mathrm{mL} / \mathrm{min})$
1500 (variable)

$27.0 \times 2.0 \times 0.0185$

1.0

$0.5 \pm 0.01$

$3.0 \pm 0.1$

60

15 (variable)

1.0 (variable)

1.2 (variable)

Adjusted for maximum signal intensity

Fassel torch

Burgener mira mist

Scott type

Nickel, 1-mm orifice diameter

Nickel, 0.7-mm orifice diameter 1.0 


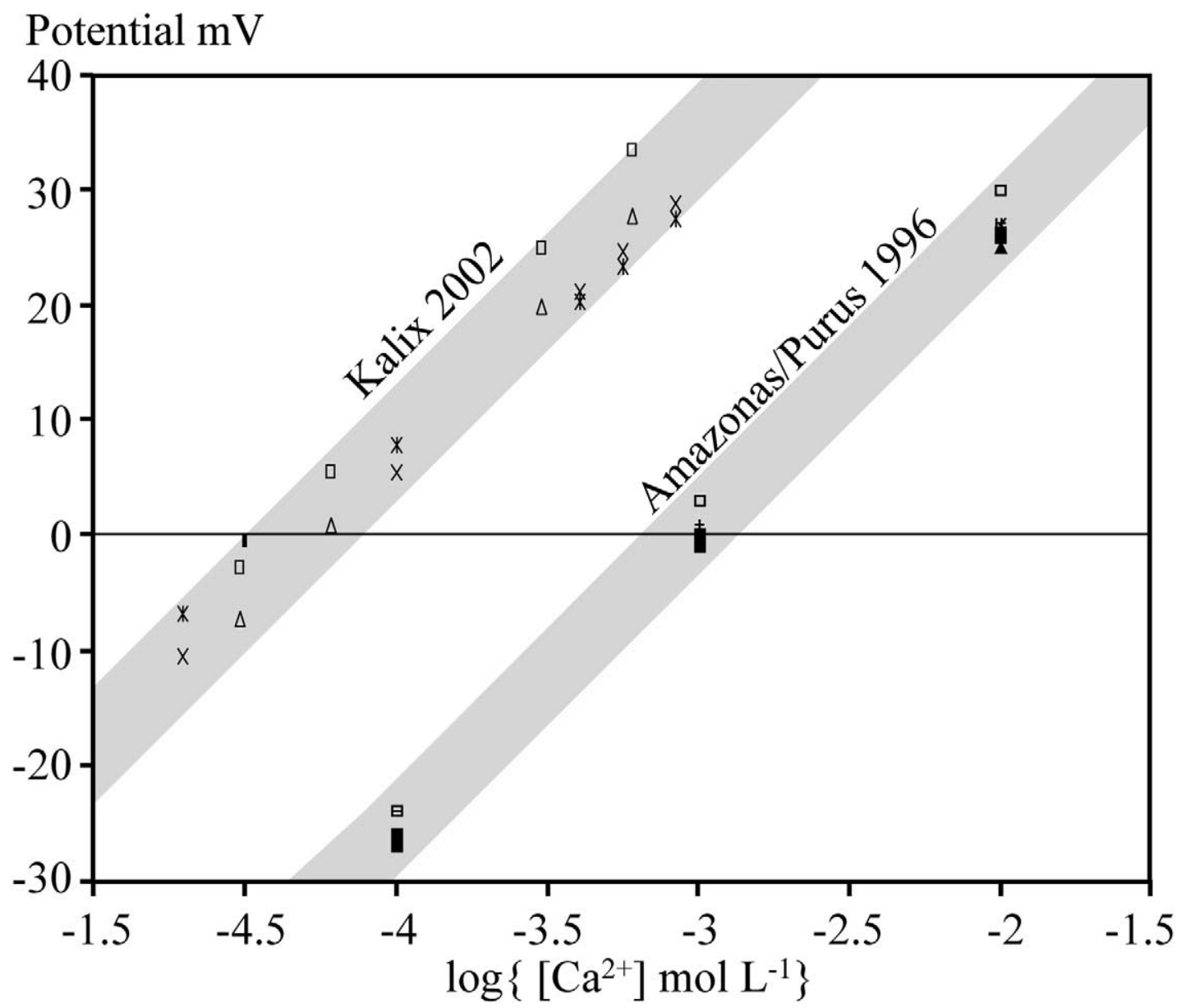

Fig. 3. Typical calibration curves for ISE measurements during the project in Amazonas/Purús 1996 and Kalix 2002. New calibrations were performed before each analysis.

Model VI for humic substances (Tipping, 1998) together with the SCAMP model for adsorption on colloidal and particulate oxides (Lofts and Tipping, 1998).

The modelling included all elements whose total concentrations exceeded $1 \mu \mathrm{mol} / \mathrm{L}$ in any sample taken: $\mathrm{Al}, \mathrm{C}, \mathrm{Ca}, \mathrm{Fe}, \mathrm{K}, \mathrm{Mg}, \mathrm{Na}, \mathrm{S}$ (although $\mathrm{Si}$ concentrations also exceeded $1 \mu \mathrm{mol} / \mathrm{L}$, its calculated particulate and colloidal concentrations were found to be indistinguishable from zero, and WHAM does not include dissolved Si species). For humic substances, we assume the $<1-\mathrm{kDa}$ fraction to be fulvic acid and the rest (i.e., $>1 \mathrm{kDa}$ ) to be humic acid. As an initial assumption, we followed Tipping's (1996) recommendation that $50 \%$ of the measured organic carbon comprises humic substances, and that these humic substances contain $50 \%$ by weight carbon. However, it is clear from our measurements that the proportion of organic carbon, as estimated by fluorometry, is considerably smaller in the fulvic $(<1-\mathrm{kDa})$ fraction (Fig. 4). The concentration of organic carbon in the $<1-\mathrm{kDa}$ fraction averages $31 \% \pm 11 \%$ of TOC. We have therefore carried out a second set of calculations where humic substances (as humic acid) are assumed to constitute $75 \%$ of the organic carbon $>1 \mathrm{kDa}$, while humic substances (as fulvic acid) constitute $50 \%$ of the organic carbon $<1 \mathrm{kDa}$. This is consistent with the values shown in Figure 4, and also with Tipping's recent suggestion that $70 \%$ humic substances may be a more appropriate number for fresh water organic carbon (E. Tipping, personal communication). The in situ $\mathrm{pH}$-values measured when the samples were taken were corrected to laboratory temperature $\left(20^{\circ} \mathrm{C}\right)$ assuming that both the river when sampled and the solutions measured in the laboratory were in equilibrium with atmospheric $\mathrm{CO}_{2}(360$ $\mu \mathrm{atm}$ ). This resulted in small positive corrections to the $\mathrm{pH}$ (maximum $0.1 \mathrm{pH}$ unit for the coldest sample). The concentrations of particulate and colloidal aluminum and iron oxides were converted from molar to weight units using the formula weights, $61 \mathrm{~g} \mathrm{~mol}^{-1}$ (Al) and $90 \mathrm{~g}$ $\mathrm{mol}^{-1}(\mathrm{Fe})$, which are given in the WHAM manual.

Free calcium concentrations were measured in three filtered fractions: prefiltered $(<100 \mu \mathrm{m}), 0.22-\mu \mathrm{m}$ permeate, and $1-\mathrm{kDa}$ permeate.

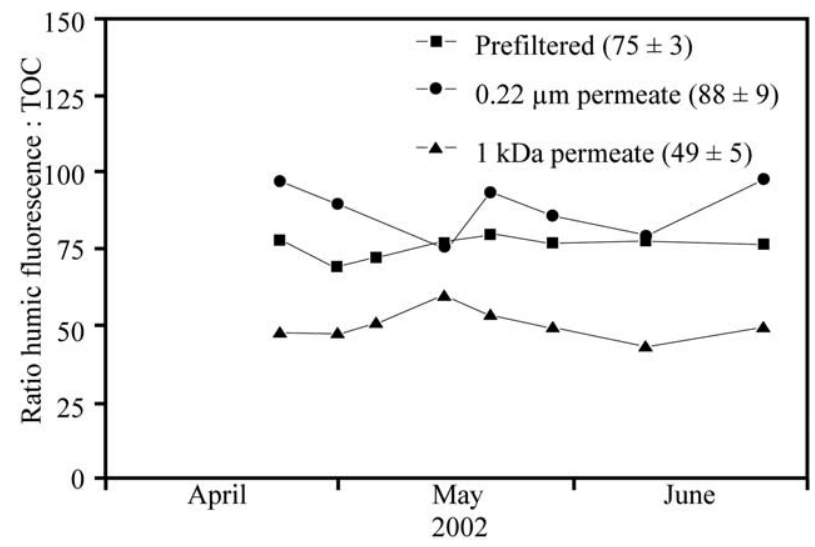

Fig. 4. Measured ratios between humic fluorescence (quinine sulphate units) and organic carbon ( $\mathrm{mmol} / \mathrm{L}$ ) in different sample fractions from the Kalix River. The figures given in the legend are average values with standard deviations for ratios in each fraction. 
Table 3. Input concentrations for WHAM calculations.

\begin{tabular}{|c|c|c|c|}
\hline Solution modelled & Particulate concentration & Colloidal concentration & "Total" concentration \\
\hline \multirow[t]{4}{*}{ Prefiltered } & Humic $=[$ particulate $\mathrm{C}]$ & Humic $=[$ colloidal $\mathrm{C}]$ & $\mathrm{Al}, \mathrm{Fe}=$ conc in $1-\mathrm{kDa}$ permeate ${ }^{\mathrm{a}}$ \\
\hline & $\mathrm{Al}=[$ particulate $\mathrm{Al}]$ & Fulvic $=[\mathrm{C}]$ in $1-\mathrm{kDa}$ permeate & $\mathrm{Ca}, \mathrm{K}, \mathrm{Mg}, \mathrm{Na} \& \mathrm{~S}=$ prefiltered conc. \\
\hline & $\mathrm{Fe}=[$ particulate $\mathrm{Fe}]$ & $\mathrm{Al}=[$ colloidal $\mathrm{Al}]$ & \\
\hline & & $\mathrm{Fe}=[$ colloidal Fe $]$ & \\
\hline \multirow[t]{4}{*}{$0.22-\mu \mathrm{m}$ permeate } & - & Humic $=[$ colloidal $\mathrm{C}]$ & $\mathrm{Al}, \mathrm{Fe}=$ conc in $1-\mathrm{kDa}$ permeate ${ }^{\mathrm{a}}$ \\
\hline & & Fulvic $=[\mathrm{C}]$ in $1-\mathrm{kDa}$ permeate & $\mathrm{Ca}, \mathrm{K}, \mathrm{Mg}, \mathrm{Na}$ and $\mathrm{S}=$ conc. in $0.22-\mu \mathrm{m}$ permeate. \\
\hline & & $\mathrm{Al}=[$ colloidal $\mathrm{Al}]$ & \\
\hline & & $\mathrm{Fe}=[$ colloidal $\mathrm{Fe}]$ & \\
\hline 1-kDa permeate & - & Fulvic $=[\mathrm{C}]$ in $1-\mathrm{kDa}$ permeate & $\mathrm{Al}, \mathrm{Fe}=$ conc in $1-\mathrm{kDa}$ permeate ${ }^{\mathrm{a}}$ \\
\hline
\end{tabular}

a "Total" $\mathrm{Al}$ and Fe concentrations in WHAM input files do not include $\mathrm{Al}$ and $\mathrm{Fe}$ in particulate and colloidal phases.

Each of these three fractions was modelled using WHAM. From the concentrations measured in each of the above three fractions, two further quantities can be calculated by difference:

$$
\begin{gathered}
\text { particulate }=[\text { prefiltered }]-[0.22-\mu \mathrm{m} \text { permeate }] \\
\text { colloidal }=[0.22-\mu \mathrm{m} \text { permeate }]-[1-\mathrm{kDa} \text { permeate }]
\end{gathered}
$$

Table 3 shows how the input concentrations for each WHAM calculation have been defined from these quantities.

\subsection{Purús/Amazonas: 1996}

The Amazon River ranks first among the world rivers due to its drainage area of $610^{6} \mathrm{~km}^{2}$ and its yearly discharge of $5.510^{9} \mathrm{~m}^{3} \mathrm{yr}^{-1}$. It represents $\sim 20 \%$ of the world fresh water flux from land to ocean (Molinier et al., 1997). Dissolved and particulate fluxes carried by the Amazon River are therefore of utmost importance in biogeochemical cycling between land and ocean.

The largest tributaries contribute with $90 \%$ of the Amazon discharge or actual drainage area. Tributaries of the Amazon River exhibit a range of chemical characteristics. They have long been classified into three types on the basis of their appearance as "white waters," "clear waters" and "black waters" (Gibbs, 1972). The Rio Solimões and Rio Negro combine at Manaus to form the Amazon River. The "black waters" from the Rio Negro are relatively acid $(\mathrm{pH}<5)$, low in total cations and rich in dissolved organic carbon. The "white waters" from the Rio Madeira, Rio Purús and the Rio Solimões show a near neutral $\mathrm{pH}$ and are relatively rich in total cations and in suspended particulate matter. In the Rio Solimões, the clay minerals of the river suspensions consist of smectites, illite and a minor amount of kaolinite, which are also present in the floodplain sediments, together with quartz and $\mathrm{Na}$ - or Ca-plagioclases, and in the Rio Negro kaolinite dominates the clay fraction of the suspension.

\subsubsection{Sampling}

Samples were taken during the 'Rio Purús Cruise' from the HiBAm project in October 1996. This cruise took place during a falling stage with low discharges in the Rio Purús and the Amazonian rivers (Fig. 5). Samples were taken along the Rio Purús (D2, D3 and D8) until the confluence with the Rio Solimões. Samples were taken in the Rio Solimões (D11) at the Manacapurù station, Rio Negro (D12) at Paricatuba station, Rio Madeira (D15), Rio Trombetas (D18) at Oriximina and for the mixed sample on the Amazon (D19) at the Òbidos station. The Tapajos River (D20) was sampled at Alter do Chão and the Amazon $50 \mathrm{~km}$ downstream from this station at Taperinha (D21) (Fig. 5). Discharges at the sampling locations were measured with an Acoustic Doppler Current Profiler (ADCP, with a 10\% reproducibility) (Guyot et al., 1998).

\subsubsection{Ultrafiltration}

Surface water samples $(0-0.5 \mathrm{~m})$ were taken and treated on board with sequential CFF (Ultrasart from Sartorius). For each sample: $50 \mathrm{~L}$ of water were filtered using clean ultrafiltration membranes with molecular cutoffs of $0.22 \mu \mathrm{m}, 100$ and $5 \mathrm{kDa}$ (Fig. 2b). All membranes were cleaned in the lab with $50 \mathrm{~L}$ of Milli-Q ultra pure water (Millepore). The first $5 \mathrm{~L}$ of sampled water were systematically discarded to

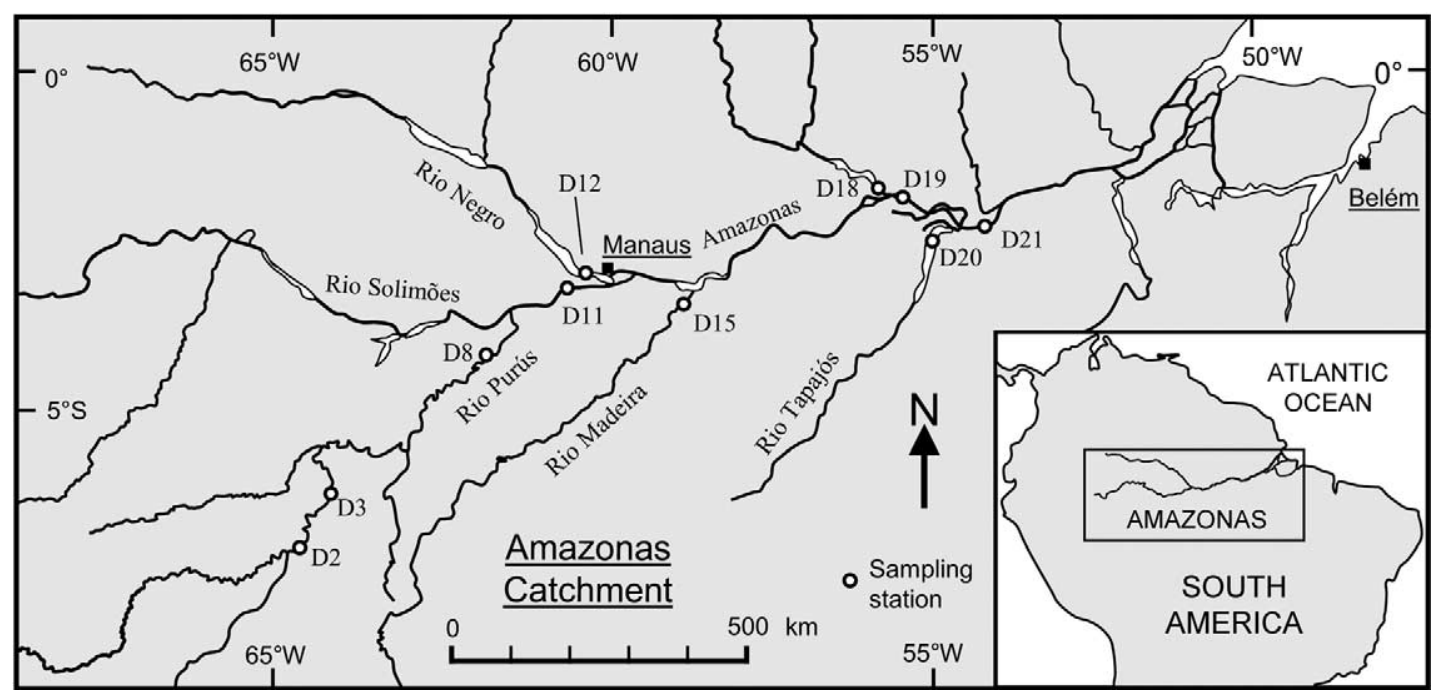

Fig. 5. The Amazonian catchment and sampling stations during the 1996 expedition. 
Table 4. Results from the Amazonas/Purús expedition 1996.

\begin{tabular}{|c|c|c|c|c|c|c|c|c|c|c|}
\hline Sample & D2 & D3 & D8 & D11 & D12 & D15 & D18 & D19 & D20 & D21 \\
\hline River & Purus & Purus & Purus & Solimões & Negro & Madeira & Trombetas & Amazonas & Tapajós & Amazonas \\
\hline Locality & Lábrea & Canutama & Aruma & Manacapuru & Manaus & Foz & Oriximiná & Óbidos & Alter do Chão & Taperinha \\
\hline $\begin{array}{l}\text { Discharge } \\
\qquad\left(\mathrm{m}^{3} \mathrm{~s}^{-1}\right)\end{array}$ & 530 & 810 & 2660 & 55,940 & 32,990 & 7410 & 2710 & 109,440 & 6500 & 124,870 \\
\hline $\begin{array}{l}\text { Conductivity } \\
\qquad\left(\mu \mathrm{S} \mathrm{cm}^{-}\right. \\
\text {1) }\end{array}$ & 77 & 77 & 51 & 96 & 8 & 68 & 15 & 54 & 14 & 48 \\
\hline $\mathrm{pH}$ & 7.2 & 6.9 & 6.6 & 7 & 5 & 7.2 & 6.7 & 6.9 & 7.4 & 6.9 \\
\hline \multicolumn{11}{|c|}{ Concentration factors for the different river samples } \\
\hline c.f. $0.22 \mu \mathrm{m}$ & 17 & 24 & 10 & 16 & 14 & 19 & 12 & 14 & 10 & 13 \\
\hline c.f. $100 \mathrm{kDa}$ & 18 & 22 & 22 & 55 & 22 & 19 & 15 & 15 & 15 & 15 \\
\hline c.f. $5 \mathrm{kDa}$ & 7 & 18 & 6 & 2 & 16 & 16 & 8 & 9 & 4 & 5 \\
\hline \multicolumn{11}{|c|}{$\mathrm{Ca}$ concentration in $\mathrm{mmol} / \mathrm{L}$ measured by ICP-AES } \\
\hline Unfiltered & 0.32 & 0.31 & 0.15 & 0.30 & 0.01 & 0.16 & 0.02 & 0.14 & 0.03 & 0.11 \\
\hline $\begin{array}{l}0.22-\mu \mathrm{m} \\
\text { retentate }\end{array}$ & 0.40 & 0.49 & 0.38 & 0.71 & 0.05 & 0.28 & 0.11 & 0.40 & 0.11 & 0.34 \\
\hline $\begin{array}{l}\text { 100-kDa } \\
\text { retentate }\end{array}$ & 0.40 & 0.42 & 0.21 & 0.46 & 0.05 & 0.26 & 0.06 & 0.24 & 0.06 & 0.21 \\
\hline $\begin{array}{l}5-\mathrm{kDa} \\
\text { retentate }\end{array}$ & 0.43 & 0.48 & 0.18 & 0.35 & 0.03 & 0.29 & 0.04 & 0.23 & 0.04 & 0.17 \\
\hline $\begin{array}{l}0.22-\mu \mathrm{m} \\
\text { permeate }\end{array}$ & 0.32 & 0.31 & 0.11 & 0.31 & 0.01 & 0.15 & 0.01 & 0.13 & 0.02 & 0.11 \\
\hline $\begin{array}{l}100-\mathrm{kDa} \\
\text { permeate }\end{array}$ & 0.31 & 0.30 & 0.11 & 0.26 & 0.01 & 0.15 & 0.01 & 0.11 & 0.02 & 0.09 \\
\hline $\begin{array}{l}\text { 5-kDa } \\
\text { permeate }\end{array}$ & 0.28 & 0.28 & 0.09 & 0.22 & 0.00 & 0.13 & 0.00 & 0.09 & 0.01 & 0.07 \\
\hline Recovery & 0.98 & 1.00 & 0.92 & 1.01 & 0.99 & 0.94 & 0.94 & 0.96 & 1.03 & 1.01 \\
\hline \multicolumn{11}{|c|}{$\mathrm{Ca}^{2+}$ concentration in $\mathrm{mmol} / \mathrm{L}$ determined by the Ca ISE } \\
\hline Unfiltered & 0.28 & 0.26 & 0.10 & 0.22 & 0.01 & 0.15 & 0.02 & 0.10 & 0.02 & 0.10 \\
\hline $\begin{array}{l}0.22-\mu \mathrm{m} \\
\text { retentate }\end{array}$ & 0.31 & 0.35 & 0.20 & 0.45 & 0.08 & 0.23 & 0.08 & 0.19 & 0.08 & 0.19 \\
\hline $\begin{array}{l}100-\mathrm{kDa} \\
\text { retentate }\end{array}$ & 0.33 & 0.26 & 0.14 & 0.38 & 0.03 & 0.22 & 0.05 & 0.19 & - & 0.16 \\
\hline $\begin{array}{l}\text { 5-kDa } \\
\text { retentate }\end{array}$ & 0.36 & 0.26 & 0.12 & 0.31 & 0.01 & 0.22 & 0.02 & 0.19 & 0.03 & 0.13 \\
\hline $\begin{array}{l}0.22-\mu \mathrm{m} \\
\text { permeate }\end{array}$ & 0.28 & 0.26 & 0.09 & 0.24 & 0.01 & 0.14 & 0.01 & 0.10 & 0.02 & 0.08 \\
\hline $\begin{array}{l}100-\mathrm{kDa} \\
\text { permeate }\end{array}$ & 0.28 & 0.26 & 0.09 & 0.22 & 0.01 & 0.14 & 0.01 & 0.09 & 0.01 & 0.08 \\
\hline $\begin{array}{l}\text { 5-kDa } \\
\text { permeate }\end{array}$ & 0.26 & 0.26 & 0.07 & 0.20 & 0.00 & 0.11 & 0.00 & 0.07 & 0.01 & 0.05 \\
\hline Recovery & 0.99 & 1.01 & 0.88 & 1.18 & 0.83 & 0.82 & 0.80 & 0.96 & 1.00 & 0.83 \\
\hline
\end{tabular}

prevent sample contamination during the filtration. Calculations for $\mathrm{Ca}$ indicate good recoveries. Detailed descriptions of mass balance calculations can be found in Hoffman et al. (1981). Organic carbon (OC) and Ca concentrations were measured in: (1) bulk untreated water, (2) in each retentate fraction and (3) in all successive permeates. Ca was determined by ICP-AES with a detection limit of $5 \mu \mathrm{mol} / \mathrm{L}$. TOC and dissolved organic carbon (DOC) concentrations were measured with a Dorhman DC analyzer as described by Patel et al. (1999).

\subsubsection{Ca ISE measurements}

Once samples were collected or ultrafiltered, the free $\mathrm{Ca}$ ions were measured on board using a Ca ion-selective electrode (Orion, 93-20), and a Metrohm reference electrode (6.0733.100). The two electrodes were connected to a digital $\mathrm{pH}$ meter (WTW, $\mathrm{pH}$ 196) reading in microvolts with an accuracy $\pm 0.1 \mathrm{mV}$. The ion-selective electrode was calibrated every day (Fig. 3). The temperature of all standard solutions and samples was allowed to stabilize $\left(\sim 25^{\circ} \mathrm{C}\right)$ before any measurements were started. Samples were collected in acid washed 50-mL HDPE plastic bottles with wide necks, and all measurements were performed while stirring with a Teflon coated magnet. For each standard or sample, when a stable potential was observed (usually after $5 \mathrm{~min}$ ) the reading was taken. An average concentration and standard deviation was calculated from these data. Figure 3 shows all calibration curves for the ISE. Solid $\mathrm{Ca}\left(\mathrm{NO}_{3}\right)_{2}$ (p.a.) and ultrapure water were used to make three standard solutions: $0.1,1$ and $10 \mathrm{mmol} / \mathrm{L} \mathrm{Ca}$.

\subsubsection{Modelling $\mathrm{Ca}$ in the amazonian rivers}

DOC concentrations converted into amount of fulvic acid expressed in kilograms per liter as well as the free calcium concentration measured by the ISE in the $5-\mathrm{kDa}$ permeate $(<5 \mathrm{kDa})$ were used as input to the model. It was assumed, that only $70 \%$ of the total amount of fulvic acid was reactive. Competition between $\mathrm{Fe}, \mathrm{Al}$ and $\mathrm{Ca}$ was taken into account as well as the effect of $\mathrm{Al}$ and $\mathrm{Fe}$ on the overall charge of the organic matter and thus their effect on the non specific binding of $\mathrm{Ca}$ (i.e., electrostatic) to the organic matter. The total amount of $\mathrm{Fe}$ and $\mathrm{Al}$ in the fraction $<0.22$ $\mu \mathrm{m}$ was used as input values for the model calculations (data in Benedetti et al., 2003). Fifty percent of the total $\mathrm{Fe}$ and $\mathrm{Al}$ concentrations in the bulk samples were used when calculations were made for samples D12 and D18. This choice is based on the distribution data of both elements previously discussed in Allard et al. (2002). They showed that for those rivers $50 \%$ of the $\mathrm{Fe}$ and $\mathrm{Al}$ in the particulate fraction are probably associated to organics. A Donnan model was used to account for the electrostatic effects during the binding of Ca (Benedetti et al., 1996, Kinniburgh et al., 1999) in combination with the NICA isotherm for the specific binding to carboxylic and phenolic type groups (Kinniburgh et al., 1999). The recently published databases (Milne et al., 2001, 2003) and the 
Table 5. Fractionation results from ultrafiltrations the Kalix 2002 project. Conc. in $\mu$ mol/L.

\begin{tabular}{|c|c|c|c|c|c|c|c|}
\hline & Free $\mathrm{Ca}$ & Complexed & Colloids & Particles & Sum & {$[\mathrm{Ca}]_{\text {Tot }}$} & $\mathrm{Sum} /[\mathrm{Ca}]_{\mathrm{Tot}}$ \\
\hline 12 Feb & $141(98)^{\mathrm{a}}$ & n.d. & $1(0.9)^{\mathrm{b}}$ & $1(0.9)^{\mathrm{b}}$ & 144 & 144 & $100 \%$ \\
\hline $11 \mathrm{Mar}$ & $145(90)$ & $11(7.0)$ & $4(2.8)^{\mathrm{c}}$ & n.d. & 161 & 144 & $112 \%$ \\
\hline 9 Apr & $126(82)$ & $10(6.8)$ & $3(2.3)$ & $13(8.5)$ & 153 & 156 & $98 \%$ \\
\hline $24 \mathrm{Apr}$ & 97 (69) & 41 (29) & $3(2.5)$ & n.d. & 141 & 141 & $100 \%$ \\
\hline 1 May & $49(90)$ & n.d. & n.d. & $5(10)$ & 54 & 62 & $87 \%$ \\
\hline 6 May & $45(68)$ & $9(13)$ & $8(13)^{d}$ & $4(5.7)^{\mathrm{d}}$ & 65 & 56 & $116 \%$ \\
\hline 15 May & $50(74)$ & $5(7.3)$ & 9 (13) & $4(5.8)$ & 68 & 68 & $101 \%$ \\
\hline 21 May & 43 (58) & 13 (17) & 14 (19) & $4(5.7)$ & 74 & 73 & $102 \%$ \\
\hline 29 May & $64(59)$ & $27(25)$ & 14 (13) & $4(3.9)$ & 110 & 91 & $120 \%$ \\
\hline 25 June & $21(26)$ & $37(45)$ & $18(23)$ & $4(5.5)$ & 81 & 95 & $85 \%$ \\
\hline
\end{tabular}

n.d. = no detection.

a (xx) Percentage of sum.

b $1 \mu \mathrm{m}$ filter used instead of $0.22 \mu \mathrm{m}$.

c $25 \mu \mathrm{m}$ filter used instead of $0.22 \mu \mathrm{m}$.

d 1 MDa filter used instead of $0.22 \mu \mathrm{m}$.

associated parameters for the NICA-Donnan model were used for the speciation calculation except for Al. For the later, parameters from Pinheiro et al. (2000) were used.

\section{RESULTS AND DISCUSSION}

\subsection{ICP-AES and ISE Concentrations in Bulk Water From the Kalix and Amazonian Rivers}

Analyses with ICP-AES and ISE in unfiltered and prefiltered water from the Kalix and Amazonian (Tables 4 and 5) rivers first of all show that the two analysis techniques render different results. About $16 \%$ of the total Ca can not be accounted for by the ISE analysis. Secondly, the results from the Amazonian and Kalix rivers show a significant correlation with one another (Fig. 6). All data from both river systems (with one exception from the Kalix River) show that on average $84 \%$ of the total calcium is present as free $\mathrm{Ca}\left(r^{2}=0.97\right)$.

Further investigations using other methods are necessary to determine how this non-free calcium is transported. CFF is the most commonly used method to collect and quantify colloidal material. However, for $\mathrm{Ca}$ it has been shown that free ions are retained during ultrafiltration (Guo et al., 2001). This makes the distinction between free $\mathrm{Ca}$ ions and colloidally associated $\mathrm{Ca}$

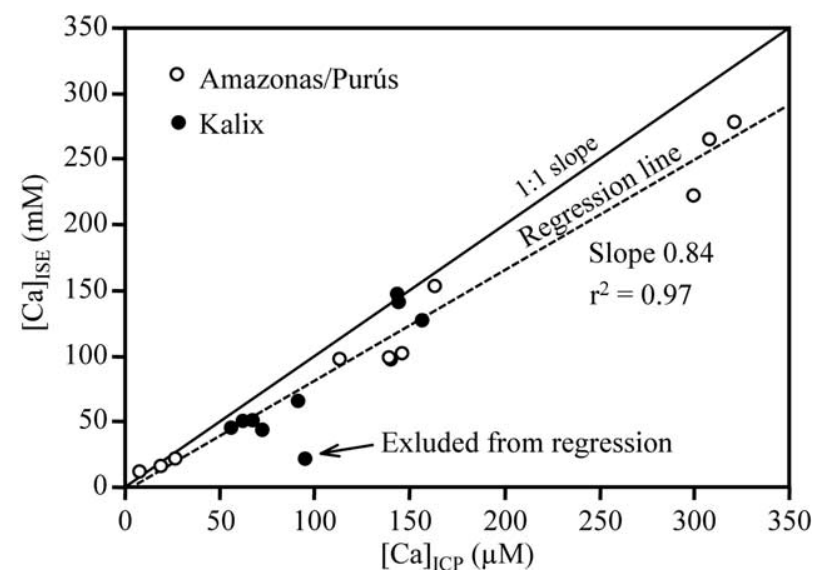

Fig. 6. Comparison between ICP-AES and ISE analyses in prefiltered (Kalix River) and unfiltered (Amazonian rivers) samples. impossible without using ISE analysis (see discussion in introduction). A thorough investigation of how $\mathrm{Ca}$ behaves during ultrafiltration, and how retention of free Ca ions should be corrected for during calculation of colloidal concentrations are therefore also presented in this paper. FlFFF has been used as independent method to establish whether the non-free $\mathrm{Ca}$ is of colloidal nature in the Kalix River samples, and the results from the CFF and FlFFF measurements are discussed in section 3.3.3.

\subsection{A Calculation Exercise for Colloidally Associated Ca, and Results From the Kalix and Amazonian Rivers}

Figure 7 shows results from two ultrafiltrations performed on Kalix River water on May 21, 2002. As can be seen in the retentate fractions, far from all enriched $\mathrm{Ca}$ is larger than the

[Ca] $\mu \mathrm{M}$

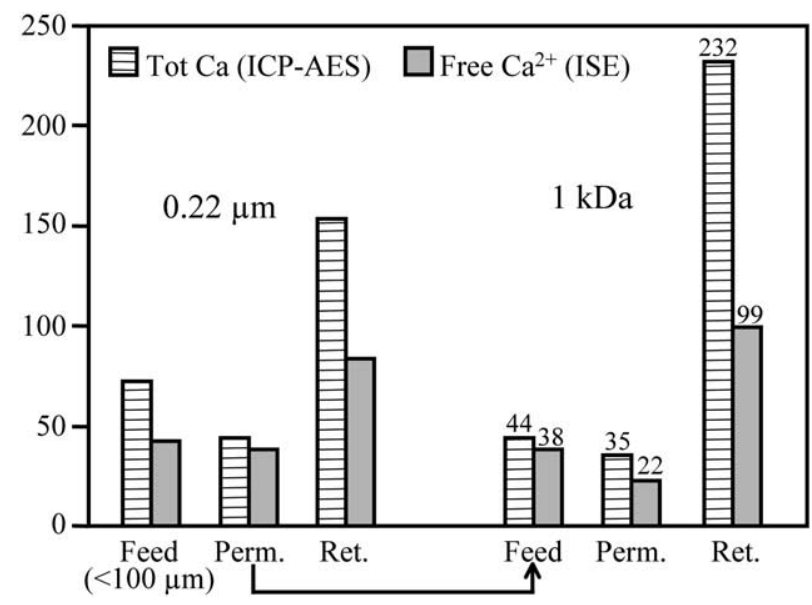

Fig. 7. Ultrafiltration results from Kalix on May 21, 2002. The two ultrafiltrations $(0.22 \mu \mathrm{m}$ and $1 \mathrm{kDa})$ show large enrichment of both colloids and dissolved $\mathrm{Ca}$ in the retentate fractions. Results from the $1-\mathrm{kDa}$ filtration are used in section 3.2 to illustrate how to correct for the retention of dissolved $\mathrm{Ca}$, hence the numbers above the bars. Permeate from the $0.22-\mu \mathrm{m}$ filtration is used as feed solution for the $1-\mathrm{kDa}$ filtration. 
pore size used. A considerable amount of free $\mathrm{Ca}$ is also enriched in both retentates.

If the colloidal concentration is calculated with Eqn. 1 using only results obtained from the ICP-AES analysis, the result will be an overestimation of colloidally bound $\mathrm{Ca}$. To illustrate the problem, the four different calculation methods for $\mathrm{Ca}$ associated to colloidal matter (section 2.1.3) are performed below with data from the sample collected on May 21.

First, Eqn. 1 is used to make a conventional calculation of colloidal material between $1 \mathrm{kDa}$ and $0.22 \mu \mathrm{m}$ (ICP-AES results from the 1-kDa ultrafiltration, Fig. 7). The concentration factor for this particular filtration was 9.25.

$$
[\text { colloidal }]_{1 \mathrm{kDa}-0.22 \mu \mathrm{m}}=(232-35) / 9.25=21 \mu \mathrm{mol} / \mathrm{L}
$$

With Eqn. 3 the colloidal concentration is calculated as the difference in concentration between the $0.22-\mu \mathrm{m}$ and $1-\mathrm{kDa}$ permeates.

$$
[\text { colloidal }]_{1 \mathrm{kDa}-0.22 \mu \mathrm{m}}=44-35=9 \mu \mathrm{mol} / \mathrm{L}
$$

However, this calculation is uncertain since the two concentrations used for the determination are not statistically different (within standard deviations of each other). This approach is therefore not recommended in this particular case.

Eqn. 4 uses the difference in concentration measured with ICP-AES and ISE in the $0.22-\mu \mathrm{m}$ permeate. This calculation of colloidally associated $\mathrm{Ca}$ also includes complexed $\mathrm{Ca}$ in the 1-kDa permeate.

$$
\text { [colloidal }]_{<0.22 \mu \mathrm{m}}=44-38=6 \mu \mathrm{mol} / \mathrm{L}
$$

As with Eqn. 3, this calculation is also uncertain. The two numbers used are close and not statistically different.

The last method (Eqn. 5) Uses the difference in concentration measured with ICP-AES and ISE in the 1-kDa retentate, divided by the concentration factor.

$$
[\text { colloidal }]_{1 \mathrm{kDa}-0.22 \mu \mathrm{m}}=(232-99) / 9.25=14 \mu \mathrm{mol} / \mathrm{L}
$$

In the case of May 21, the result of the conventional calculation (Eqn. 1) is $133 \%, 250 \%$ and $50 \%$ higher than the results obtained using Eqn. 3, 4 and 5, respectively.

The colloidal concentrations of calcium in the Kalix and Amazonian rivers have been calculated using the four different equations defined in section 2.1.3 and demonstrated above. The colloidal fraction in the Amazonian rivers is defined as material between $5 \mathrm{kDa}$ and $0.22 \mu \mathrm{m}$, instead of $1 \mathrm{kDa}$ and $0.22 \mu \mathrm{m}$ as for the Kalix data. The results displayed in Figure 8 show that with Eqn. 1 and 3, and to some extent Eqn. 4, the Ca associated with the colloidal phase is overestimated compared to results obtained with Eqn. 5, which should be the most robust and reliable method. This is true both for temporal variations (Kalix River, Fig. 8a) and for geographical variations (Purús/Amazonian rivers, Fig. 8b). The results presented in Figure 8 emphasize the necessity to correct for retention of free $\mathrm{Ca}$ ions during ultrafiltration when calculating the colloidal concentration.

It is important to perform a calculation of recovery or massbalance to verify the integrity of the calculated results. Average ultrafiltration recoveries for Ca from the Kalix River are listed in Table 1, and from the Amazonian rivers in Table 4.

\subsection{Kalix River}

\subsubsection{Geochemical variations during the Spring-Flood event}

The Ca concentration and water discharge during winter flow is mainly governed by the inflow of groundwater. In late April and early May the snow melts in the woodland area and maximum spring flood usually occurs in mid-May. In 2002 the water discharge increased from a minimum value of $71 \mathrm{~m}^{3} \mathrm{~s}^{-1}$ in mid-April to maximum flow of $1640 \mathrm{~m}^{3} \mathrm{~s}^{-1}$ in early May (Fig. 9). The total $\mathrm{Ca}$ concentration decreased from 156 $\mu \mathrm{mol} / \mathrm{L}$ (April 9, Table 5) to $56 \mu \mathrm{mol} / \mathrm{L}$ on May 6 , due to the dilution of base flow water with melt water percolating through the upper soil layers. At the same time, the TOC concentration increased from $\sim 0.20$ to $0.75 \mathrm{mmol} / \mathrm{L}$. This means that the TOC-flux increased $>80$ times from $\sim 15 \mathrm{Mg} \mathrm{d}^{-1}$ to $\sim 1.3 \mathrm{Gg}$ $\mathrm{d}^{-1}$. The $\mathrm{pH}$-value is closely correlated to the TOC concentration and drops $\sim 1 \mathrm{U}$ during maximum spring flood, due to the presence of acid organic material.

\subsubsection{Retention of free Ca during ultrafiltration}

Figure 10 shows Ca concentrations measured with ICP-AES and ISE in prefiltered water and $<1-\mathrm{kDa}$ permeate during the sampled period. The ICP-AES analysis of the $<1-\mathrm{kDa}$ permeate is generally lower than the ISE result from the prefiltered sample, which indicates that free $\mathrm{Ca}$ ions are retained during ultrafiltration. Throughout the sampled period concentrations determined with ISE is generally lower than ICP-AES results in $<1-\mathrm{kDa}$ permeates. This corresponds $\mathrm{Ca}$ associated to very small colloids which can pass through the 1-kDa membrane but not measured with ISE. This fraction is defined in this article as complexed Ca (see section 2.1.2 for definitions).

Results from the midwinter sample in February indicate that no measurable amount of $\mathrm{Ca}$ is present in the colloidal phase. Since no colloidal material seems to be present (identical ISE and ICP-AES results for the prefiltered water and $<1-\mathrm{kDa}$ permeate, Fig. 10), the difference in concentration between the prefiltered water and the $<1-\mathrm{kDa}$ permeate ( $\Delta$ Conc. $\sim 27$ $\mu \mathrm{mol} / \mathrm{L})$ is an artifact from the ultrafiltration, where free $\mathrm{Ca}$ is enriched in the retentate, and hence lost from the permeate. ICP-AES and ISE analyses of the $1-\mathrm{kDa}$ retentate solution support this theory since no significant colloidal material can be found in this fraction either. Approximately $20 \%$ of the free $\mathrm{Ca}$ was retained during this particular ultrafiltration, where the concentration factor was 11.80 and the filtration settings as described in Table 1.

The concentration in the permeate solution can at any time be predicted using Eqn. 6:

$$
\ln C_{\mathrm{p}}=\ln \left(P_{\mathrm{c}} \times C_{\mathrm{f}}^{0}\right)+\ln (c . f .) \times\left(1-P_{\mathrm{c}}\right)
$$

where $P_{\mathrm{c}}$ is the permeation coefficient $\left(C_{\mathrm{p}} / C_{\mathrm{f}}\right), C_{\mathrm{p}}$ and $C_{\mathrm{f}}$ are the concentrations in the permeate and feed solutions, $C_{\mathrm{f}}^{0}$ is the initial concentration of permeable species in the feed solution and c.f. the concentration factor (Logan and Jiang, 1990; Kilduff and Weber, 1992; Logan, 1999).

The ratio between $\left[\mathrm{Ca}^{2+}\right]$ measured with ISE in permeate and retentate solutions $\left(C_{\mathrm{p}} / C_{\mathrm{r}}\right)$ after a completed ultrafiltration can be considered as an average $C_{\mathrm{p}} / C_{\mathrm{f}}$ ratio. The permeation coefficient of 0.85 reported for Trinity River water 

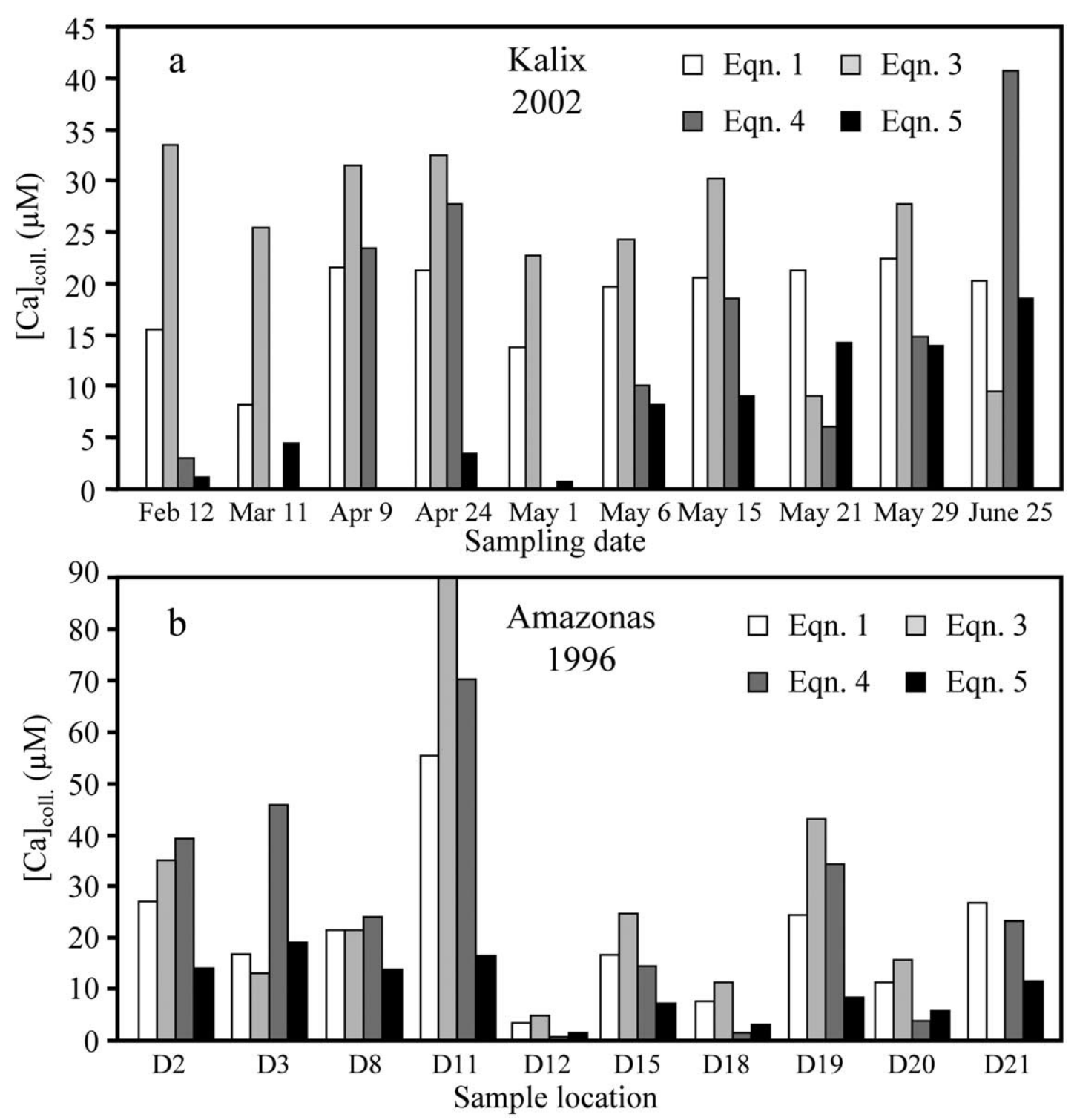

Fig. 8. Calculations of colloidal $\mathrm{Ca}$ in the Kalix (a) and Amazonian (b) rivers using the four different equations defined in section 2.1.3.

in Guo et al. (2001) is close to the $C_{\mathrm{p}} / C_{\mathrm{r}}$ ratios $0.81,0.74$ and 0.83 measured in this study during winter flow from February to early April when concentrations of organic carbon were low (Fig. 9).

The $\mathrm{Ca}^{2+} / \mathrm{Ca}_{\text {tot }}$ ratio decreases from close to 1.0 during February and March to between 0.6 and 0.8 during the spring flood. The permeation coefficient of free $\mathrm{Ca}$ also decreases from $\sim 0.8$ to between 0.2 and 0.6 with the lowest value during maximum discharge when the TOC concentration reaches its peak. When the spring flood starts, the fractionation of $\mathrm{Ca}$ changes and ISE results from prefiltered samples are significantly lower than ICP-AES measurements. This indicates that there is a colloidal fraction of $\mathrm{Ca}$ present.

\subsubsection{FlFFF results}

The CFF results showing a colloidal fraction of $\mathrm{Ca}$ (section 3.2) were verified by FIFFF-HR ICP-MS measurements. Figure 11 shows FlFFF-HR ICP-MS fractograms for $\mathrm{Ca}, \mathrm{C}$ and $\mathrm{Fe}$ in samples from April 9 (winter conditions in the Kalix River), May 1 (spring flood event) and May 21 (after the spring flood event).

The geochemical changes in the river during the transition from winter to summer conditions are clearly seen when looking at the fractograms of the colloidal carrier phases, and the fractionation of $\mathrm{Ca}$ and other elements associated with the colloids show corresponding shifts in size distribution (Fig. 11). The indications of two separate colloidal carrier phases, Fe (iron oxyhydroxides) and C (humic substances), in the Kalix River has been discussed previously (Ingri et al., 2000). Organic (humics) and inorganic (Fe-rich) colloidal carrier phases have also been identified in other freshwaters along the Swedish west coast. The association of trace elements with these carrier phases has been investigated in more detail in Lyvén et al. (2003). The fractionation of $\mathrm{Ca}$ and other elements associated with the colloids show corresponding shifts in size distribution. Organic (humics) and inorganic (Fe-rich) colloi- 


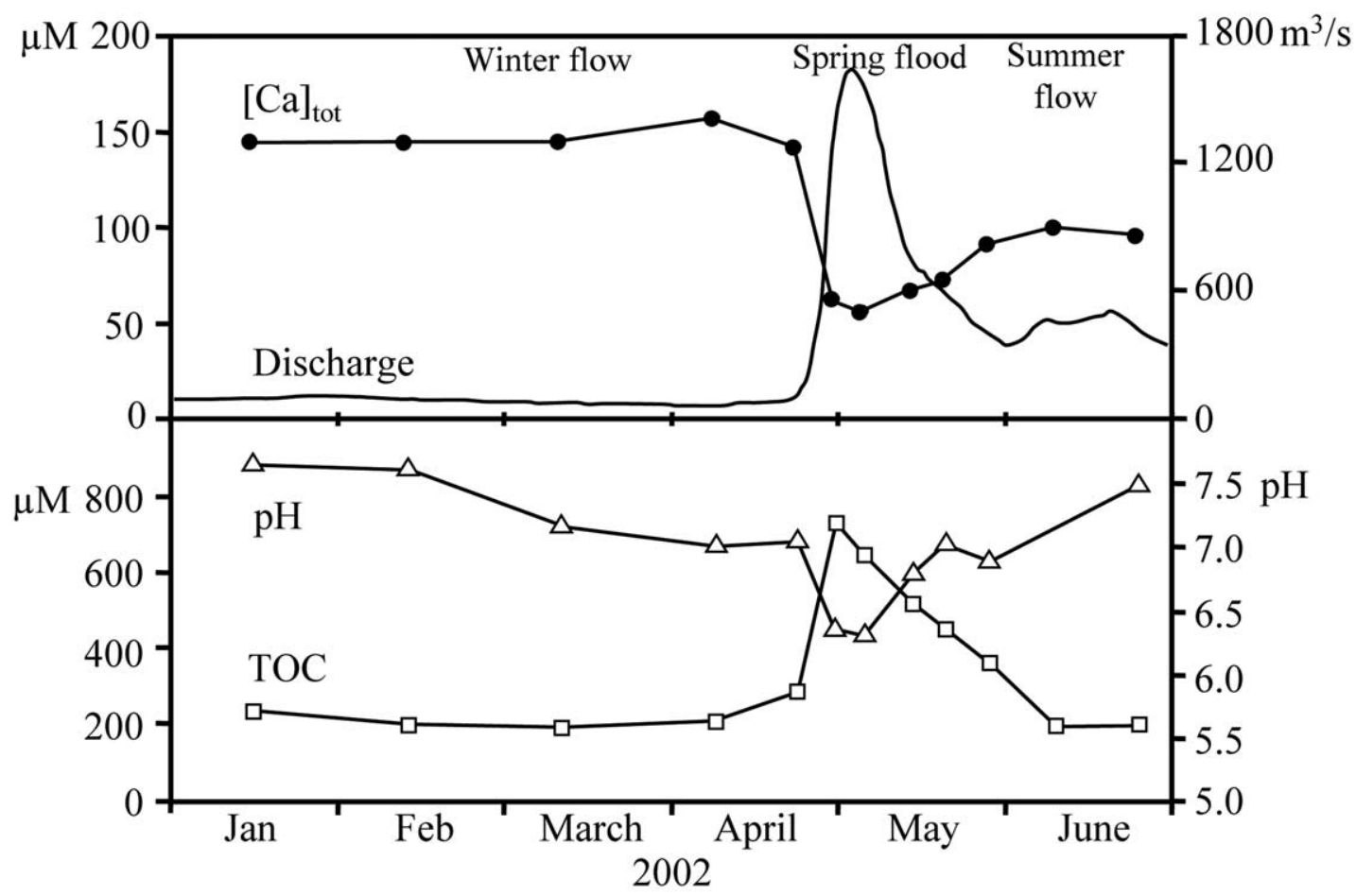

Fig. 9. Changes in major parameters during winter flow, spring flood and summer flow in the Kalix River.

dal carrier phases have also been identified in other freshwaters along the Swedish west coast. The association of trace elements with these carrier phases has been investigated in more detail in Lyvén et al. (2003).

The FlFFF-HR ICP-MS results support the CFF findings that $\mathrm{Ca}$ is associated to colloidal material (Fig. 11). During winter conditions the size distribution of colloidally bound $\mathrm{Ca}$ is quite broad and correlates poorly with humic substances. However, during and after the spring flood event the size distribution of colloidal $\mathrm{Ca}$ follows that of $\mathrm{C}$ (shown by the UV-signal). The colloidal concentration of $\mathrm{C}$ peaks at maximum flow during the spring flood and the same can be seen for $\mathrm{Ca}$, although the colloidal $\mathrm{Ca}$ concentration does not decrease

[Ca] $\mu \mathrm{M}$

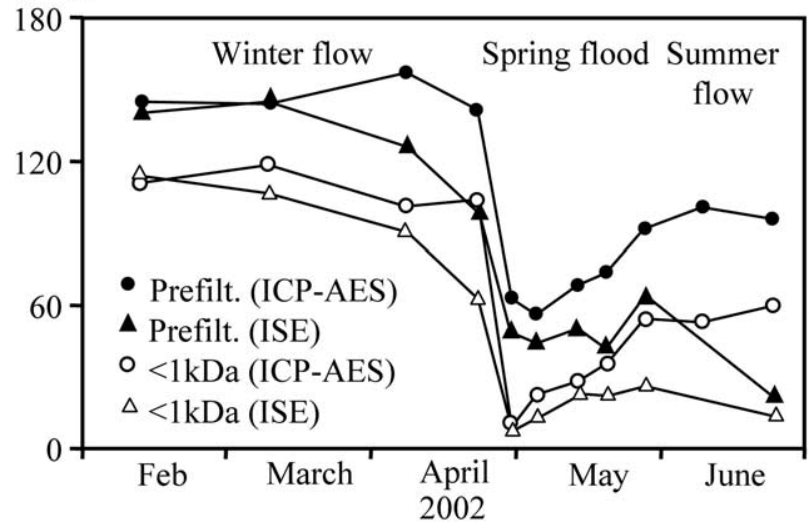

Fig. 10. Ca-concentrations measured with ICP-AES and ISE in prefiltered samples and 1-kDa permeates. as much after the spring flood compared to C. Evidence of colloidally bound $\mathrm{Ca}$, associated more strongly with $\mathrm{C}$ than with $\mathrm{Fe}$, was also found in the study by Lyvén et al. (2003).

It is important, however, to use some caution when comparing colloidal concentrations determined with CFF and FlFFF. $\mathrm{Ca}$ can be associated with humic colloids through two different mechanisms: specific binding to humic ligand groups, and non-specific accumulation of $\mathrm{Ca}$, as a charge-balancing ion, in the diffuse layer surrounding the humic colloid. Both the WHAM and NICA-Donnan models distinguish explicitly between these two association mechanisms, although the terminology is somewhat different. CFF, which works in a largely constant ionic medium, should retain both classes of colloidassociated calcium in the retentate. FlFFF, in contrast, involves exchange of the sample's ionic medium for ammonium nitrate during the equilibration and elution stages. There is therefore a possibility that non-specifically bound $\mathrm{Ca}$ in the colloids' diffuse layer can be replaced with ammonium during these stages, with the result that FlFFF data would indicate lower colloidal Ca concentrations than CFF. Replacement of specifically bound $\mathrm{Ca}$ with ammonium is assumed to be unlikely over the relatively short time scale involved.

\subsubsection{Ca fractionation}

Calculations of the Ca-fractionation in 10 water samples are presented in Figure 12 and Table 5. These calculations are derived from direct analysis (with ICP-AES and ISE) combined with results from calculations defined in section 2.1.3. The concentration of free $\mathrm{Ca}$ (light grey) is measured with ISE in prefiltered samples. Complexed $\mathrm{Ca}$ (medium grey) is defined as the difference between ICP-AES and ISE in the 1-kDa perme- 

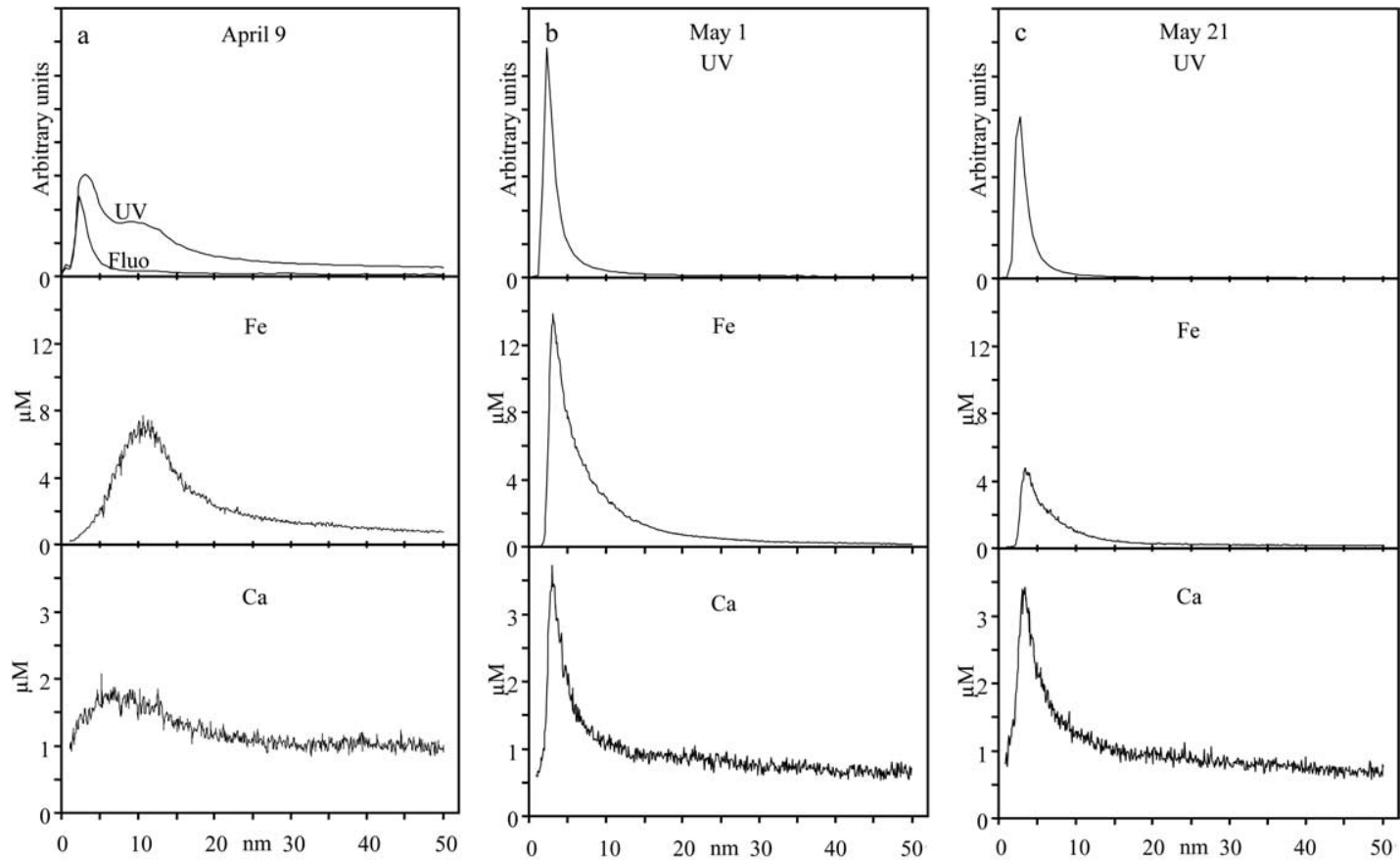

Fig. 11. Comparison of the size distribution of organic material (UV), [Fe] and [Ca] before the spring flood (a), during peak discharge (b) and after the springflood (c) in the Kalix River 2002. Although C was not quantified during the FIFFF-HR ICP-MS runs, the UV peak height has been normalized with the TOC concentration $(<0.22 \mu \mathrm{m})$ to give an estimate to the relative $\mathrm{C}$ concentration changes. In the April 9 sample the UV signal exhibits a double peak. The first peak is UV absorbance of humic material (as seen with the fluorescence signal) and the second peak is due to light scattering from the larger Fe colloids (the latter peak correlates very well with the size distribution of Fe).

ate. The colloidal fraction between $1 \mathrm{kDa}$ and $0.22 \mu \mathrm{m}$ (dark grey) is the difference between ICP-AES and ISE in the 1-kDa retentate divided by the concentration factor (Eqn. 5). The particulate concentration (black) is the difference between the concentration measured with ICP-AES in the prefiltered sample and the $0.22-\mu \mathrm{m}$ permeate, and adjusted for retention of free $\mathrm{Ca}$ in the $0.22-\mu \mathrm{m}$ retentate. According to these calculations, free $\mathrm{Ca}$ is the dominant species during base flow in winter before the spring flood. However, a significant difference can be observed between the ICP-AES and the ISE analyses in the prefiltered water collected on April 9 (Fig. 10). This is clearly before the spring flood and discharge has not yet started to

$[\mathrm{Ca}] \mu \mathrm{M}$

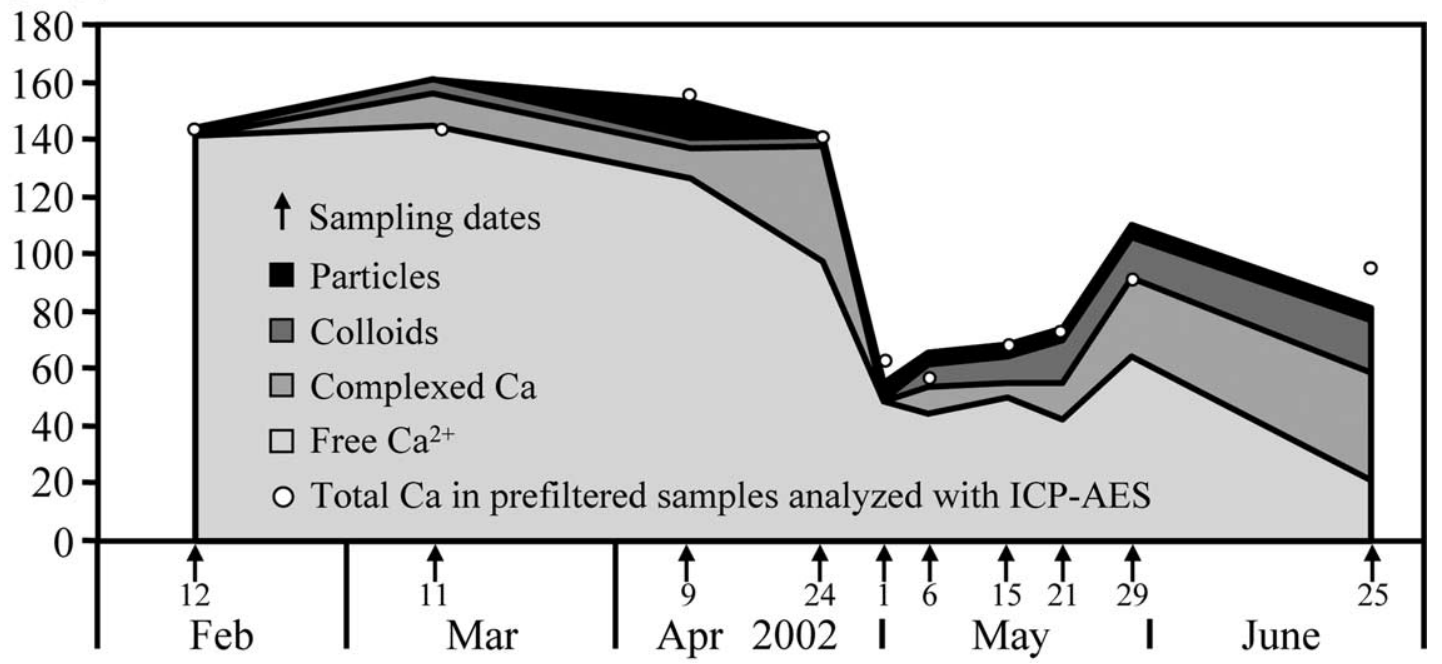

Fig. 12. A calculated fractionation of $\mathrm{Ca}$ in the Kalix River based on ultrafiltration fractions analyzed using ICP-AES and ISE. The colloidal concentration is calculated using Eqn. 5. 


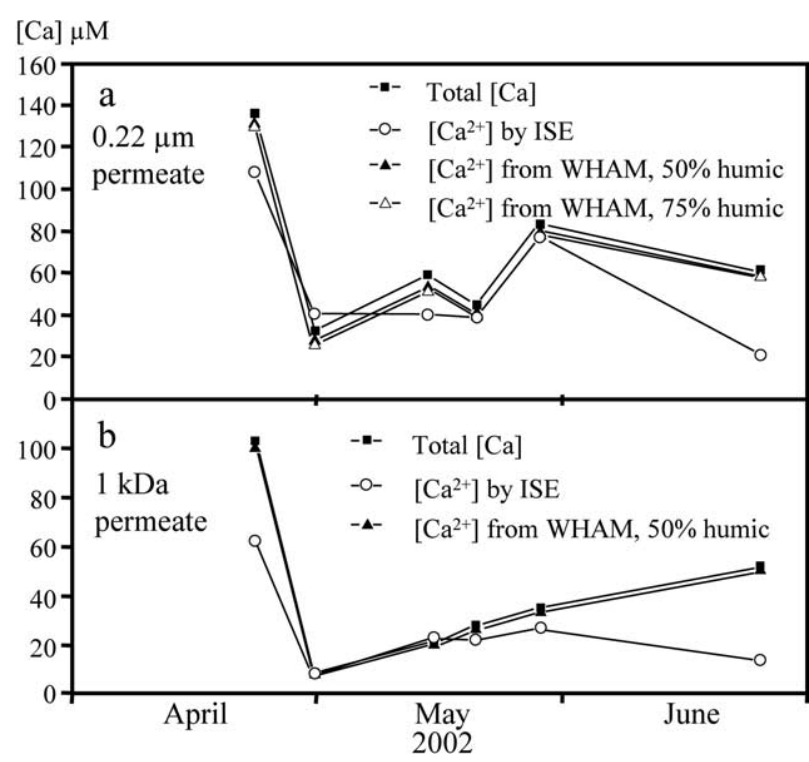

Fig. 13. Comparison between the concentrations measured with ICP-AES and Ca-ISE and results from WHAM modeling in the Kalix River. (a) $0.22-\mu \mathrm{m}$ permeate: WHAM calculations are shown for $50 \%$ and $75 \%$ humic acid in the $>1-\mathrm{kDa}$ TOC. (b) $1-\mathrm{kDa}$ permeate.

increase and results similar to the ones from February and March were expected. The break-up of the ice cover in early April is a possible explanation for the particulate and/or colloidal fraction detected on April 9, since large ice floes have the ability to create turbulence and stir up material from the river bed. A distinct peak in complexed Ca (light grey) is seen just before the spring flood starts. During the spring flood, the dominance of free $\mathrm{Ca}$ decreases and the presence of both colloids and complexed $\mathrm{Ca}$ is apparent.

The particulate $\mathrm{Ca}$ concentration $(0.22-100 \mu \mathrm{m})$ is fairly constant $(\sim 5 \mu \mathrm{mol} / \mathrm{L})$ throughout the period and always $<10 \%$ of the total concentration.

A dramatic change in fractionation can be observed in the sample collected in June. The $\left[\mathrm{Ca}^{2+}\right]_{\text {free }} /[\mathrm{Ca}]_{\text {tot }}$ ratio, which is close to 1.0 during winter, drops sharply from 0.70 on May 29 to 0.23 on June 25 (Fig. 10, Table 5). Thus the free Ca species would no longer be the dominant fraction of the total concentration. It should be noted, however, that recoveries for $\mathrm{Ca}$ were only $85 \%$ on June 25 . Therefore great caution should be used when interpreting this data point.

\subsection{Modelling}

\subsubsection{Modelling of $\mathrm{Ca}$ in the kalix river}

Modelling of the prefiltered samples showed that WHAM seriously underestimated the concentrations of particulate $\mathrm{Ca}$, which is interpreted to mean that particulate $\mathrm{Ca}$ is present in forms other than adsorbed onto to particulate humics and aluminium and iron oxides. Since ISE measurements show very similar free $\mathrm{Ca}$ concentrations in the prefiltered samples and the $0.22-\mu \mathrm{m}$ permeates, the nature of the particulate Ca was not felt to be relevant to this study and was not pursued further.

Modelling of the $0.22-\mu \mathrm{m}$ permeate (Fig. 13a) shows reasonable agreement between the WHAM calculations of free $\mathrm{Ca}$ and the ISE measurements, with the notable exception of June 25 , where only a low proportion of the total $\mathrm{Ca}$ was measurable by ISE. The result is little changed by assuming $75 \%$ rather than $50 \%$ humic acid in the $>1-\mathrm{kDa}$ TOC. A similar pattern emerges from the 1-kDa permeate (Fig. 13b), except that there is now also a significant difference between WHAM calculations and ISE measurements on April 24.

These results indicate that the free $\mathrm{Ca}$ concentrations measured with the ISE are broadly comparable with thermodynamic speciation calculations with the WHAM model, with the notable exception of June 25 .

\subsubsection{Modelling of $\mathrm{Ca}$ in the amazonian rivers}

The accuracy of the colloidal Ca concentrations in the different Amazonian rivers (Fig. 5) has been controlled by modelling the $\mathrm{Ca}$ speciation using NICA-Donnan in the different river water samples. Here, the free calcium is used as input value to calculate the total amount of $\mathrm{Ca}$ in the fraction $<0.22$ $\mu \mathrm{m}$, and to estimate the amount of colloidal $\mathrm{Ca}$ in this fractions. The later can then be compared to the measured colloidal $\mathrm{Ca}$. The results of the calculations are shown in Figure 14, and the calculated values are in very good agreement with total calcium concentrations measured by ICP in the fraction $<0.22 \mu \mathrm{m}$ (Fig. 14a). This validates the modelling approach used here and the hypothesis made for the calculations. The calculated calcium fractionation is very similar for the different Amazonian water samples. Free calcium represents $80 \%$ to $96 \%$ of the total $\mathrm{Ca}$ in the bulk water and the rest corresponds to calcium diffusely bound (i.e., in the Donnan phase) to the organic matter. Calcium specific binding to carboxylic and phenolic type groups always represents $<0.13 \%$ of the total calcium concentration in the fraction $<0.22 \mu \mathrm{m}$. This result is similar to the findings of Dupré et al. (1999) who showed with Sr isotopic measurements that $<0.22 \mu \mathrm{m} \mathrm{Sr}$ was totally present in an exchangeable form. The calculations show that the complexed fraction is probably negligible in most cases. The amount of colloidal Ca calculated with the model is also in very good agreement with the amount of colloidal Ca calculated earlier with Eqn. 5 (Fig. 14b). This result shows that this calculation method is robust and that the other methods will overestimate the amount of $\mathrm{Ca}$ because they probably take into account $\mathrm{Ca}$ that is artificially concentrated by the ultrafiltration process (Guo et al., 2001). The conclusion drawn from the model calculations, that $\mathrm{Ca}$ is mainly bound into the Donnan phase (i.e., electrostatic binding), is also supported by the fact that the amount of colloidal Ca decreases as the conductivity increases (Fig. 14b). It was shown by Kinniburgh et al. (1999) that when the ionic strength increases, the screening potential of the solution increases and the electrostatic contribution to the overall binding decreases. Moreover, as ionic strength increases the organic matter may undergo aggregation as shown for polymer gels (Chin et al., 1998) and proposed by Benedetti et al. (1996). It reduces the amount of $\mathrm{Ca}$ in the Donnan gel and therefore in the colloidal phase as shown in Figure 14b for measured colloidal Ca.

We state here that significant quantities of colloidal $\mathrm{Ca}$ in organic rich rivers $(10 \%-25 \%)$ can be detected. This colloidal calcium may promote the aggregation of the dissolved organic matter, as reported for marine aggregates by Chin et al. (1998). This is especially important for dissolved organic 
[Ca total] model $\mu \mathrm{M}$

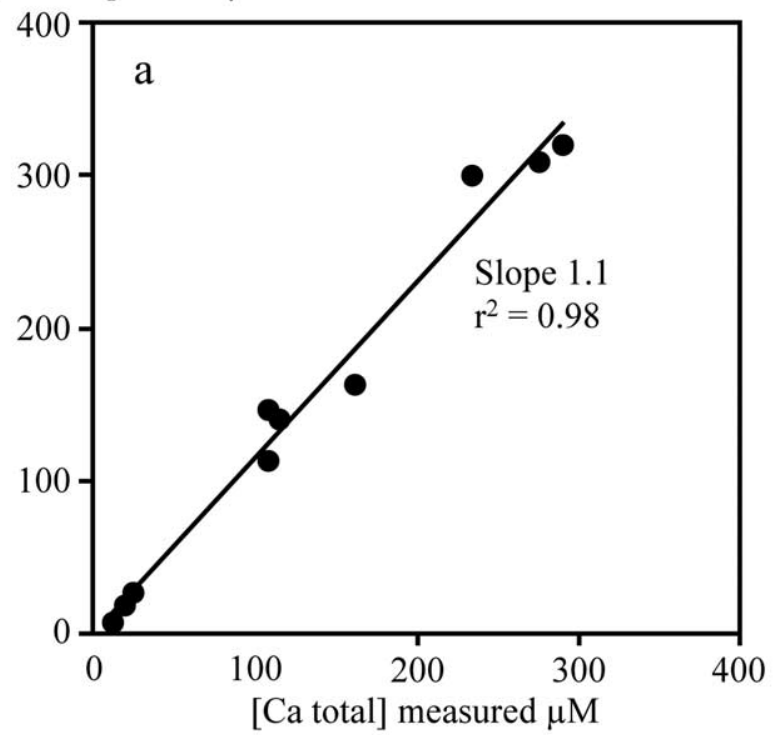

Conductivity $(\mu \mathrm{S} / \mathrm{cm})$

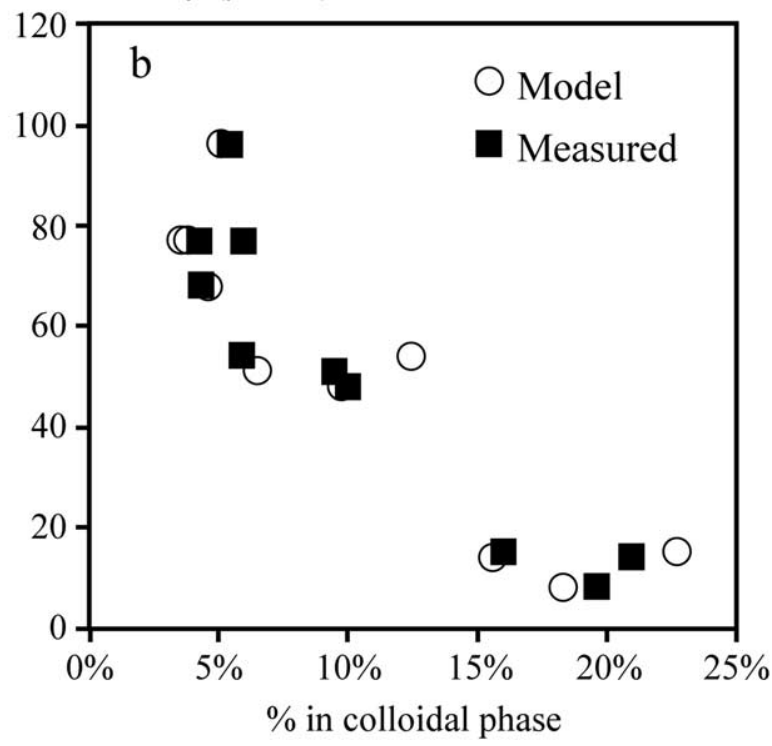

Fig. 14. Model results from the Rio Purús/Amazonas expedition. (a) The correlation between modeled and measured total Ca concentrations in the fraction $<0.22 \mu \mathrm{m}$. (b) Both modeled and measured percentages of colloidal $\mathrm{Ca}$ show a decreasing trend towards high conductivity.

carbon budget of the Amazon in the mixing zone (between sample D11 and D19) where low conductivity, organic rich water (D12) meets high conductivity, calcium rich water (D11). It was shown that during this mixing process $1.9 \mathrm{Tg}$ of DOC was lost per year (Aucour et al., 2003) part of it may have been promoted by the colloidal $\mathrm{Ca}$ evidence here.

\subsubsection{Comparison of modelling in the kalix and amazonian rivers}

Since two different speciation models have been used in connection with the Kalix (WHAM) and Amazon data (NICA-

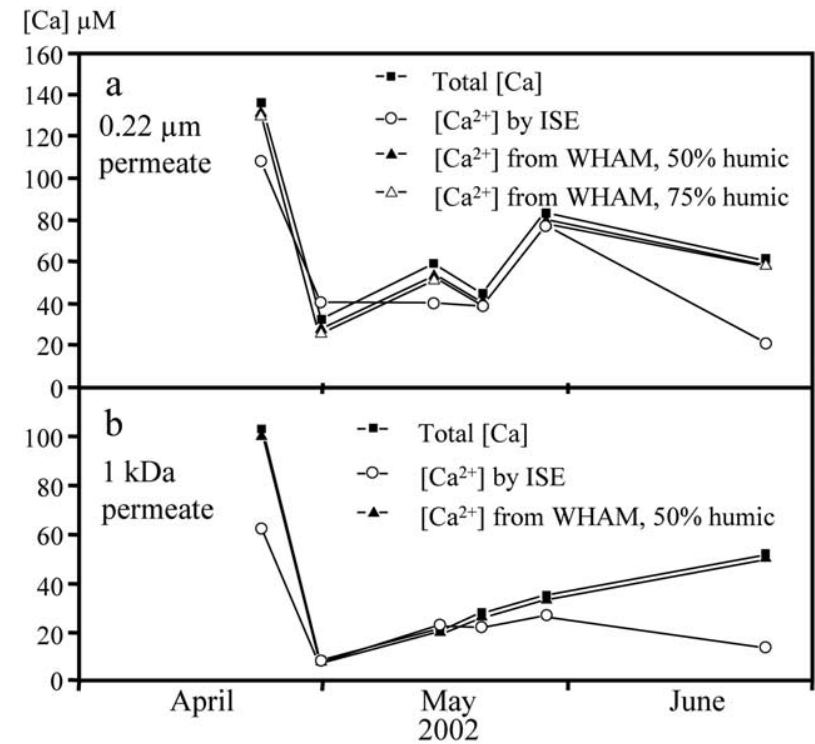

Fig. 15. A comparison of generated data using the WHAM and NICA-Donnan models on 5-kDa filtered water from the Amazon/Purús rivers (a) and $0.22-\mu \mathrm{m}$ filtered water from the Kalix River (b) show excellent agreement between the two models.

Donnan), we have compared the results of these modelling approaches on individual samples from each area (Fig. 15). We find that the two models are in excellent agreement in respect of the calculated fraction of free $\mathrm{Ca}$, although there are differences in the calculated distributions of $\mathrm{Ca}$ between different mechanisms of binding to humic substances.

\section{CONCLUSIONS}

Analysis of unfiltered and prefiltered samples from the Amazonian and Kalix rivers using ISE and ICP-AES were in excellent agreement, and show that a significant amount of $\mathrm{Ca}$, besides free $\mathrm{Ca}$ and particulate $\mathrm{Ca}$, is present. Further analysis with ISE and ICP-AES of solutions from ultrafiltrations reveal that colloidally bound $\mathrm{Ca}$ actually is retained and detected. In agreement with previous studies, a significant amount of free $\mathrm{Ca}$ is also retained together with the colloidal material. Results with a correlation coefficient of $r^{2}=0.97$ suggest that on average $84 \%$ of the total $\mathrm{Ca}$ is free $\mathrm{Ca}$.

Both the CFF and FIFFF methods independently show that colloidal $\mathrm{Ca}$ is present in the Kalix River. FlFFF measurements show that $\mathrm{Ca}$ associates more strongly with carbon-rich colloids than with iron-rich colloids.

The properties of colloidal material in fresh waters are still largely unexplored. While it is known that organic matter is an important carrier phase for metals, quantitative descriptions are hampered by the lack of information on the nature of the organic colloidal material. Here, for instance, it has been shown that the character of DOC in the Kalix River varies with size, material with low molecular weight having a significantly lower fluorescence response per mole of carbon than organic matter passing a $0.2-\mu \mathrm{m}$ filter. This indicates a significant difference in composition and structure, which can be expected to result in a different capacity for binding metals.

It has been shown previously that for a purified fraction of 
organic matter (humic substances), the two modelling approaches give similar results (Christensen et al., 1998). Here, we show that for natural dissolved organic matter the two models also predict the same amount of colloidal $\mathrm{Ca}$ although different assumptions are used for each model. This confirms the robustness of the two models and validates their use to obtain information on the speciation of chemical elements in complex geochemical environments.

The approach of using an ion-selective electrode in combination with conventional ICP-AES analysis adds a new dimension to the interpretation of ultrafiltration data. For $\mathrm{Ca}$ it has now been shown that dissolved ions as well as colloidal material can be enriched in the retentate fraction during ultrafiltration. By using the conventional method to determine the colloidal concentration, it is assumed that only species larger than the membrane pore size are affected by retention. This is not the case. Without appropriate corrections, based on ISE information (or equivalent), the amount of colloidal $\mathrm{Ca}$ can be greatly overestimated.

Assessment of how other elements behave during ultrafiltration requires reliable data of the free ion concentrations. The use of ISE might be a step in the right direction, but it is still too early to conclude whether the retention of free ions during ultrafiltration is restricted to $\mathrm{Ca}$ or if a general problem exists.

Acknowledgments-The authors would like to thank Anders Henriksson, Johan Gelting-Nyström, Helena Skoglund and Jerry Forsberg at Luleå University of Technology for their assistance during collection and processing of samples. We are grateful to Rickard Hernell and Ilia Rodushkin at Analytica Corp. for technical support and help during sample preparation and analysis. This work was supported by the Swedish Research Council, grants G-AA/GU 640-2645/1999 (Ingri) and G 5103-20005567/2000 (Turner). The work on the Amazonian rivers was financed by the Programme d'Etude de la Géosphère Intertropicale and Programme Sol et Erosion supported by the Institut de Recherche et de Développement (IRD) and the Centre National de la Recherche Scientifique. The authors would also like to thank the Hibam project team (IRD/CNPq/ANEEL). We are grateful for the feed-back given by associate editor Dr. Eggleston and two anonymous reviewers.

Associate editor: C. M. Eggleston

\section{REFERENCES}

Allard T., Ponthieu M., Weber T., Filizola N., Guyot J.-L., and Benedetti M. (2002) Nature and properties of suspended solids in the Amazon Basin. Bull. Soc. Geol. France 173, 67-75.

Aucour A.-M., Tao F.-X., Moreira-Turcq P., Seyler P., Sheppard S., and Benedetti M. F. (2003) The Amazon River: Behaviour of metals $(\mathrm{Fe}, \mathrm{Al}, \mathrm{Mn})$ and dissolved organic matter in the initial mixing at the Rio Negro/Solimões confluence. Chem. Geol. 197, 271-285.

Beckett R. and Hart B. T. (1993) Use of field-flow fractionation techniques to characterize aquatic particles, colloids and macromolecules. In Environmental Particles (eds. J. Buffle and H. P. van Leeuwen), Vol. 2, pp. 165-205. Lewis Publishers.

Beckett R., Jue Z., and Giddings J. C. (1987) Determination of molecular weight distributions of fulvic and humic acids using flow field-flow fractionation. Environ. Sci. Technol. 21, 289-295.

Benedetti M. F., van Riemsdijk W. H., Koopal L. K., Kinniburgh D. G., and Milne C. J. (1996) Metal ion binding to natural organic matter: From the model to the field. Geochim. Cosmochim. Acta 60, 25032513.

Benedetti M. F., Mounier S., Filizola N., Benaim J., and Seyler P. (2003) Carbon and metal concentrations, size distributions and fluxes in major rivers of the Amazon basin. Hydrol. Proc. 17, 1363-1377.
Benner R. (1991) Ultra-filtration for the concentration of bacteria, viruses and dissolved organic matter. Geophys. Monogr. 63, 275280.

Buffle J., Deladoey P., and Haerdi W. (1978) The use of ultrafiltration for the separatioin and fractionation of organic ligands in fresh waters. Anal. Chim. Acta 101, 339-357.

Buffle J., Wilkinson K. J., Stoll S., Filella M., and Zhang J. (1998) A generalized description of aquatic colloidal interactions: The threecolloidal component approach. Environ. Sci. Technol. 32, 28872899.

Chin W.-C., Orellana M. O., and Verdugo P. (1998) Spontaneous assembly of marine dissolved organic matter into polymer gels. Nature 391, 568-572.

Christensen J. B., Tipping E., Kinniburgh D. G., Grøn C., and Christensen T. H. (1998) Proton binding by groundwater fulvic acids of different age, origins, and structure modeled with the Model V and NICA-Donnan model. Environ. Sci. Technol. 32, 3346-3355.

Dai M., Buesseler K., Ripple P., Andrews J., Belastock R. A., Gustafsson Ö., and Moran S. B. (1998) Evaluation of two cross-flow ultrafiltration membranes for isolating marine organic colloids. Mar. Chem. 62, 117-136.

Dupré B., Viers J., Dandurand J.-L., Polve M., Benezeth P., Vervier P., and Braun J.-J. (1999) Major and trace elements associated with colloids in organic-rich river waters: Ultrafiltration of natural and spiked solutions. Chem. Geol. 160, 63-80.

Dynesius M. and Nilsson C. (1994) Fragmentation and flow regulation of river systems in the northern third of the world. Science 266, 753-762.

Eyrolle F., Benedetti M. F., Benaim J. Y., and Février D. (1996) The distribution of colloidal and dissolved organic carbon, major elements, and trace elements in small tropical catchments. Geochim. Cosmochim. Acta 60, 3643-3656.

Fromm E. (1965) Beskrivning till jordartskartan över norrbottens län, nedanför lappmarksgränsen. SGU Ser. C 39, 1-236.

Gaal G. and Gorbatschev R. (1987) An outline of the Precambrian evolution of the Baltic Shield. Precam. Res. 35, 15-52.

Gee D. G. and Zachrisson E. (1979) The Caledonides in Sweden. SGU Ser. C 796, 1-48.

Gibbs R. J. (1972) Water chemistry of the Amazon River. Geochim. Cosmochim Acta 36, 1061-1066.

Giddings J. C. (1993) Field-flow fractionation-Analysis of macromolecular, colloidal, and particulate materials. Science 260, 14561465 .

Giddings J. C., Yang F. J., and Myers M. N. (1976) Theoretical and experimental characterization of flow field-flow fractionation. Anal. Chem. 48, 1126-1132.

Greenamoyer J. M. and Moran S. B. (1996) Evaluation of an Osmonics spiral-wound cross-flow filtration system for sub- $\mu \mathrm{m}$ sampling for $\mathrm{Cd}, \mathrm{Cu}$ and $\mathrm{Ni}$ in seawater. Mar. Chem. 55, 153-163.

Guo L., Coleman C. H., Jr., and Santschi P. H. (1994) The distribution of colloidal and dissolved organic carbon in the Gulf of Mexico. Mar. Chem. 45, 105-119.

Guo L., Hunt B. J., and Santschi P. H. (2001) Ultrafiltration behavior of major ions ( $\mathrm{Na}, \mathrm{Ca}, \mathrm{Mg}, \mathrm{F}, \mathrm{Cl}$, and $\mathrm{SO}_{4}$ ) in natural waters. Wat. Res. 35, 1500-1508.

Gustafsson Ö., Buesseler K. O., and Gschwend P. M. (1996) On the integrity of cross-flow filtration for collecting marine organic colloids. Mar. Chem. 55, 93-111.

Guyot J. L., Filozola N., Guimaraes V., and Johnson A. I. (1998) Amazon suspended sediment yield measurements using an Acoustic Doppler Current Profiler (ADCP): First results. IAHS-AISHPublication 253, 109-115.

Hassellöv M., Lyvén B., Haraldsson C., and Sirinawin W. (1999) Determination of continuous size and trace element distribution of colloidal material in natural water by on-line coupling of flow field-flow fractionation with ICP-MS. Anal. Chem. 71, 3497-3520.

Hoffman M. R., Yost E. C., Eisenreich S. J., and Maier W. J. (1981) Characterization of soluble and colloidal-phase metal complexes in river water by ultrafiltration. A mass-balance approach. Envion. Sci. Technol. 15, 655-661.

Ingri J., Widerlund A., Land M., Gustafsson Ö., Andersson P. S., and Öhlander B. (2000) Temporal variations in the fractionation of the 
rare earth elements in a boreal river; the role of colloidal particles. Chem. Geol. 166, 23-45.

Kilduff J. and Weber W. J., Jr. (1992) Transport and separation of organic macromolecules in ultrafiltration prosesses. Environ. Sci. Technol. 26, 569-577.

Kinniburgh D. G., van Riemsdijk W. H., Koopal L. K., Borkovec M., Benedetti M. F., and Avena M. J. (1999) Ion binding to natural organic matter: Competition, heterogeneity, stoichiometry and thermodynamic consistency. Colloids Surf., A 151, 147-166.

Larsson J., Gustafsson Ö., and Ingri J. (2002) Evaluation and optimization of two complementary cross-flow ultrafiltration systems toward isolation of coastal surface water colloids. Environ. Sci. Technol. 36, 2236-2241.

Lofts S. and Tipping E. (1998) An assemblage model for cation binding by natural particulate matter. Geochim. Cosmochim. Acta 62, $2609-2625$

Logan B. (1999) Environmental Transport Processes. John Wiley, New York.

Logan B. and Jiang Q. (1990) Molecular size distributions of dissolved organic matter. J. Environ. Imaging 116, 1046-1062.

Lyvén B., Hassellöv M., Haraldsson C., and Turner D. R. (1997) Optimisation of on-channel preconcentration in flow field-flow fractionation for the determination of size distributions of low molecular weight colloidal material in natural waters. Anal. Chim. Acta 357, 187-196.

Lyvén B., Hassellöv M., Turner D. R., Haraldsson C., and Andersson K. (2003) Competition between iron- and carbon-based colloidal carriers for trace metals in fresh water assessed using Flow FieldFlow Fractionation coupled to ICPMS. Geochim. Cosmochim. Acta 67, 3791-3802.

Milne C. J., Kinniburgh D. G., and Tipping E. (2001) Generic NICADonnan model parameters for proton binding by humic substances. Environ. Sci. Technol. 35, 2049-2059.
Milne C. J., Kinniburgh D. G., van Riemsdijk W. H. and Tipping E. (2003) Generic NICA-Donnan model parameters for metal-ion binding by humic substances. Environ. Sci. Technol. 37, 958-971.

Molinier M., Guyot J.-L., Callede J., Guimaraes V., Oliveira E., and Filizola N.(1997) Hydrologie du bassin amazonien, 24-41. In Environnement et Développement en Amazonie Brésilienne (ed. $\mathrm{H}$ Théry). Publ. Belin, Paris, France.

Patel N., Mounier S., Guyot J.-L., Benamou C., and Benaim J. Y. (1999) Fluxes of dissolved and colloidal organic carbon, along the Purus and Amazonas rivers (Brasil). Sci. Tot. Eniviron. 229, 53-64.

Pinheiro J. P., Mota A. M., and Benedetti M. F. (2000) Effect of aluminium competition on lead and cadmium binding to humic acids at variable ionic strength. Environ. Sci. Technol. 34, 51375143 .

Salbu B., Björnstad H. E., Lindsröm N. S., Lydersen E., Brevik E. M., Rambaek J. P. and Paus P. E. (1985) Size fractionation techniques in the determination of elements associated with particulate of colloidal material in natural fresh waters. Talanta 32, 907-913.

Tipping E. (1996) Information for WHAM users [distributed with the WHAM computer programme]. Institute of Freshwater Ecology.

Tipping E. (1998) Humic ion-binding model VI: An improved description of the interactions of protons and metal ions with humic substances. Aquat. Geochem. 4, 3-48.

Tipping E. and Hurley M. A. (1992) A unifying model of cation binding by humic substances. Geochim. Cosmochim. Acta 56 , 3627-3641.

Viers J., Dupré B., Polvé M., Schott J., Dandurand J.-L., and Braun J.-J. (1997) Chemical weathering in the drainage basin of a tropical watershed (Nsimi-Zoetele site, Cameroon): Comparison between organic-poor and organic-rich waters. Chem. Geol. 140, 181-206.

Wells M. L. and Goldberg E. D. (1991) Occurrence of small colloids in sea water. Nature 353, 342-346. 